\title{
2012s-05
}

\section{The Value of Multivariate Model Sophistication: An Application to pricing Dow Jones Industrial Average Options}

\author{
Jeroen V.K. Rombouts, Lars Stentoft, Francesco Violante
}

\section{Série Scientifique \\ Scientific Series}

\author{
Montréal \\ Février 2012
}

(C) 2012 Jeroen V.K. Rombouts, Lars Stentoft, Francesco Violante. Tous droits réservés. All rights reserved. Reproduction partielle permise avec citation du document source, incluant la notice (C)

Short sections may be quoted without explicit permission, if full credit, including (C) notice, is given to the source.
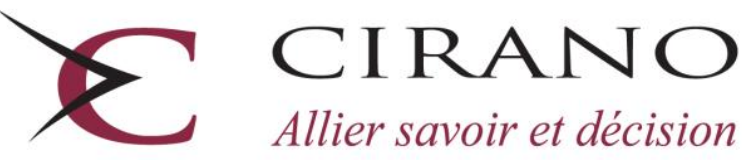

Allier savoir et décision

Centre interuniversitaire de recherche en analyse des organisations 


\section{CIRANO}

Le CIRANO est un organisme sans but lucratif constitué en vertu de la Loi des compagnies du Québec. Le financement de son infrastructure et de ses activités de recherche provient des cotisations de ses organisations-membres, d'une subvention d'infrastructure du Ministère du Développement économique et régional et de la Recherche, de même que des subventions et mandats obtenus par ses équipes de recherche.

CIRANO is a private non-profit organization incorporated under the Québec Companies Act. Its infrastructure and research activities are funded through fees paid by member organizations, an infrastructure grant from the Ministère du Développement économique et régional et de la Recherche, and grants and research mandates obtained by its research teams.

\section{Les partenaires du CIRANO}

\section{Partenaire majeur}

Ministère du Développement économique, de l'Innovation et de l'Exportation

\section{Partenaires corporatifs}

Autorité des marchés financiers

Banque de développement du Canada

Banque du Canada

Banque Laurentienne du Canada

Banque Nationale du Canada

Banque Royale du Canada

Banque Scotia

Bell Canada

BMO Groupe financier

Caisse de dépôt et placement du Québec

CSST

Fédération des caisses Desjardins du Québec

Financière Sun Life, Québec

Gaz Métro

Hydro-Québec

Industrie Canada

Investissements PSP

Ministère des Finances du Québec

Power Corporation du Canada

Rio Tinto Alcan

State Street Global Advisors

Transat A.T.

Ville de Montréal

\section{Partenaires universitaires}

École Polytechnique de Montréal

HEC Montréal

McGill University

Université Concordia

Université de Montréal

Université de Sherbrooke

Université du Québec

Université du Québec à Montréal

Université Laval

Le CIRANO collabore avec de nombreux centres et chaires de recherche universitaires dont on peut consulter la liste sur son site web.

Les cahiers de la série scientifique (CS) visent à rendre accessibles des résultats de recherche effectuée au CIRANO afin de susciter échanges et commentaires. Ces cahiers sont écrits dans le style des publications scientifiques. Les idées et les opinions émises sont sous l'unique responsabilité des auteurs et ne représentent pas nécessairement les positions du CIRANO ou de ses partenaires.

This paper presents research carried out at CIRANO and aims at encouraging discussion and comment. The observations and viewpoints expressed are the sole responsibility of the authors. They do not necessarily represent positions of CIRANO or its partners. 


\title{
The Value of Multivariate Model Sophistication: An Application to pricing Dow Jones Industrial Average Options
}

\author{
Jeroen V.K. Rombouts ${ }^{\dagger}$, Lars Stentoft ${ }^{\dot{*}}$, Francesco Violante ${ }^{\S}$
}

\begin{abstract}
Résumé / Abstract
We assess the predictive accuracy of a large number of multivariate volatility models in terms of pricing options on the Dow Jones Industrial Average. We measure the value of model sophistication in terms of dollar losses by considering a set 248 multivariate models that differ in their specification of the conditional variance, conditional correlation, and innovation distribution. All models belong to the dynamic conditional correlation class which is particularly suited because it allows to consistently estimate the risk neutral dynamics with a manageable computational effort in relatively large scale problems. It turns out that the most important gain in pricing accuracy comes from increasing the sophistication in the marginal variance processes (i.e. nonlinearity, asymmetry and component structure). Enriching the model with more complex correlation models, and relaxing a Gaussian innovation for a Laplace innovation assumption improves the pricing in a smaller way. Apart from investigating directly the value of model sophistication in terms of dollar losses, we also use the model confidence set approach to statistically infer the set of models that delivers the best pricing performance.
\end{abstract}

Mots clés/Keys words : Option pricing, economic loss, forecasting, multivariate GARCH, model confidence set.

Codes JEL : C10, C32, C51 C52, C53, G10

\footnotetext{
* Financial support from CIRPEE is gratefully acknowledged.

$\dagger$ HEC Montréal, CIRANO, CIRPEE and Université catholique de Louvain, CORE, B-1348, Louvain-la-Neuve, Belgium. Correspondence: HEC Montreal, 3000, chemin de la Côte-Sainte-Catherine. Tel.: +1 514-340-646.

Fax.: +1 514 340-6469. E-mail: jeroen.rombouts@hec.ca

\#EC Montréal, CIRANO, CIRPEE and CREATES.

${ }^{\S}$ Maastricht University and Université catholique de Louvain, CORE, B-1348, Louvain-la-Neuve, Belgium.
} 


\section{Introduction}

Multivariate volatility models have been used extensively to model financial data such as stock returns, interest rates, and exchange rates. The resulting dynamics take into account the interaction and correlation between assets and are therefore more realistic. Forecasts from these models are typically needed as inputs in empirical asset pricing. For example, there is quite a large body of work on evaluating a small number of low dimensional models in terms of portfolio management, see e.g. Fleming, Kirby, and Ostdiek (2001), Fleming, Kirby, and Ostdiek (2003), Engle and Colacito (2006), Voev (2009), and Chiriac and Voev (2011). Much less attention has been devoted to the evaluation of multivariate volatility models in the context of derivative pricing where neglecting the correlation may lead to severe mispricings. The main reason for this likely is the lack of a flexible general framework. For example, the existing applications of discrete time models in e.g. van den Goorbergh, Genest, and Werker (2005) and Zhang and Guégan (2008) are limited to low dimensional, i.e. bivariate, models and the multivariate stochastic volatility models of e.g. Gourieroux and Sufana (2010) and Da Fonseca, Grasselli, and Tebaldi (2007) are inherently very complex and rely heavily on having option data available for calibration. In a recent paper, Rombouts and Stentoft (2011) fill this gap by directly modeling the dynamics of the underlying stocks using multivariate models for asset returns. They demonstrate the existence of an equivalent martingale measure, characterize the risk neutral dynamics, and provide a feasible way for pricing options.

This paper investigates the value of model sophistication by considering a large number of high dimensional GARCH models and measuring performance in terms of Dow Jones Industrial Average (DJIA) option pricing accuracy. This approach is appealing because we get immediately a sense of the short, medium, and long run forecasting behavior of the models, rather than focussing on specific horizons. Furthermore, since the option price does not only depend on the conditional variance matrix but also on other conditional moments, we are actually able to evaluate the full forecasting model, i.e. level, variance, and innovation distribution. The setup we work with specifies the multivariate risk neutral return distribution and therefore allows to price any option written on the vector of underlying assets. We choose to price the index option for which true prices are available, so that we can measure the models' pricing accuracy by contrasting predicted option prices with the observed ones. The accuracy of the pricing is evaluated by means of several loss functions like in Hansen and Lunde (2005) 
for example. Apart from investigating directly the value of model sophistication by ordering the models according to their pricing performances, we also use the model confidence set (MCS) approach of Hansen, Lunde, and Nason (2011), to statistically infer the set of best models.

In the empirical option pricing literature, there is strong evidence that models beyond standard Gaussian dynamic volatility models can substantially improve pricing performance when using univariate models. Examples in the continuous time stochastic volatility context are among others Bakshi, Cao, and Chen (1997), Bates (2000), Bates (1991), Eraker (2004), and Pan (2002). More advanced discrete time models have been used in Christoffersen and Jacobs (2004), Christoffersen, Heston, and Jacobs (2006), Christoffersen, Jacobs, Ornthanalai, and Wang (2008), Heston and Nandi (2000), Hsieh and Ritchken (2005), Stentoft (2005), and Stentoft (2008). Our aim is to identify the degree of multivariate model sophistication required to obtain the most accurate pricing. In principle, the higher the model complexity the higher the precision of the pricing, thus its economic value measured in dollars. However, as argued by Giacomini and White (2006), in real data applications more sophisticated models may overfit the data, and thus be outperformed by (possibly) misspecified but more parsimonious models characterized by a lower estimation uncertainty. In this paper, we estimate 248 multivariate GARCH models differing in three dimensions: their specification of the conditional variance, conditional correlation, and innovation distribution. We focus on dynamic conditional correlation (DCC) models which is not coincidental. In fact, being characterized by idiosyncratic risk premia, the risk neutral dynamics for the vector of underlying asset returns provided in Rombouts and Stentoft (2011) allow for the usual factorization of the likelihood of these models, see Engle (2002). Thus, the models can be consistently estimated in two steps (first the variances and then the correlation matrix) rendering the estimation feasible in the thirty dimensional setting of the DJIA constituents.

With respect to the model for the conditional variances of the marginal processes, we consider the entire universe of suitable univariate GARCH models available in the literature, see Xekalaki and Degiannakis (2010) and Bollerslev (2010) for extensive surveys. By doing this, we are able to quantify the economic value of different strategies in modeling the conditional variance, i.e., i) as a linear versus non-linear function of the squared innovations, ii) modeling asymmetry versus the symmetric response of the variance to the sign of the shocks, iii) di- 
rect specification of the conditional variance versus a functional transformation, iv) constant versus time varying parameters, and v) single components versus multi-components models. In terms of correlation dynamics, we first aim to assess wether allowing for simple common dynamics in correlation outperforms the hypothesis of constant correlation. Then, we further increase the complexity of the models by allowing for idiosyncratic dynamics (i.e., diagonal DCC) and asymmetry in the correlation (i.e., asymmetric DCC) respectively. Finally, since the variable of interest, i.e. the expected index price at some future point in time, is an integral under the future risk neutral price density, and therefore not only a function of the first two conditional moments, we evaluate the multivariate models not only under the assumption of a Gaussian innovation distribution but also under the multivariate Laplace distribution which has fatter tails.

We evaluate the model performance using a direct evaluation of economic quantities (option prices). This is in contrast to Laurent, Rombouts, and Violante (2011) and Caporin and McAleer (2010) for example, who perform large scale comparisons of multivariate GARCH models using statistical criteria to evaluate statistical quantities (variance matrices). These papers rank volatility models on the basis of their ability to replicate volatility paths, and being the latter unobservable, need a proxy (typically computed by using high frequency data) of the conditional variance matrix. This requires that the loss function must have a specific functional form in order to avoid distortions in the ranking (Hansen and Lunde (2006) and Patton (2009), Laurent, Rombouts, and Violante (2009)). The advantage of our evaluation is that by forecasting option prices for which we observe the true prices, we do not need to rely on a proxy. Thus, the problem of inconsistency of the ranking does not arise and virtually any loss function can be used.

Our results suggest that in general more complicated models provide better option pricing forecasts. It turns out that the most important improvement in pricing comes from increasing the sophistication in the marginal variance processes. Enriching the model with more complex correlation models, and relaxing a Gaussian innovation for a Laplace innovation assumption provides smaller economic gains when considering the entire sample of option prices. Overall, increasing model sophistication can reduce the dollar loss up to $60 \%$. The model that performs best, according to the MCS test, is the two component threshold GARCH in combination with an asymmetric DCC structure and Laplace innovations. When we look at the pricing 
performance for different levels of moneyness, we find that the out-of-the-money contracts, which have a low average price, are more difficult to price but increasing the complexity of the model still pays off generally. Also, regarding the maturity of the options, it turns out that the best performance is for short maturity options, with very close performance between the different models.

It should be noted that, as the DJIA options are based on an equally weighted portfolio, the model comparison is based on average dynamics. However, the evaluation could equally well be conducted in terms of other types of contracts, for instance options on the maximum or minimum of the assets, which depend on other aspects of the forecasted multivariate distribution. Unfortunately, data on such options is not readily available and we therefore limit our attention to the exchange traded average options.

The rest of the paper is organized as follows: Section 2 introduces the Dow Jones Industrial Average data. In Section 3, we discuss the theoretical framework used for pricing multivariate options, including the various multivariate models to be considered. Section 4 contains the empirical results. Finally, Section 5 contains concluding remarks.

\section{Data}

In this section, we introduce the Dow Jones Industrial Average data. We start by defining the index. We then provide descriptive statistics for the returns of the 30 constituents as well as for the aggregate index. Finally we provide an overview of the index option data.

\section{$2.1 \quad$ DJIA return data}

The Dow Jones Industrial Average (DJIA) is a price-weighted index, which is composed of 30 of the largest and most liquid stocks listed on the NYSE and NASDAQ exchanges. The index is calculated by dividing the sum of the prices of the component stocks by a number called the DJIA divisor or Dow divisor. The index divisor is updated periodically and adjusted to offset the effect of stock splits and any other change in the component stocks. This ensures consistency of the index value through time.

As of November 21, 2005, the companies in Table 1 constituted the DJIA index. At that 
Table 1: Description of Dow Jones constituent companies

\begin{tabular}{lllll}
\hline \hline & Ticker & Company & Industry & Date Added \\
\hline 1 & AA & Alcoa & Aluminum & $1959-06-01$ \\
2 & AIG & American International Group & Property \& Casualty Insurance & $2004-04-08$ \\
3 & AXP & American Express & Consumer finance & $1982-08-30$ \\
4 & BA & Boeing & Aerospace \& defense & $1987-03-12$ \\
5 & CAT & Caterpillar & Construction \& mining equipment & $1991-05-06$ \\
6 & C & Citigroup & Banking & $1997-03-17$ \\
7 & DD & EI DuPont de Nemours & Commodity chemicals & $1935-11-20$ \\
8 & DIS & Walt Disney & Broadcasting \& entertainment & $1991-05-06$ \\
9 & GE & General Electric & Conglomerate & $1907-11-07$ \\
10 & GM & General Motors & Automobiles & $1925-08-31$ \\
11 & HD & Home Depot & Home improvement retailers & $1999-11-01$ \\
12 & HON & Honeywell International & Aerospace \& defense & $1925-12-07$ \\
13 & HPQ & Hewlett-Packard & Diversified computer systems & $1997-03-17$ \\
14 & IBM & International Business Machines & Computer services & $1979-06-29$ \\
15 & INTC & Intel & Semiconductors & $1999-11-01$ \\
16 & JNJ & Johnson \& Johnson & Pharmaceuticals & $1997-03-17$ \\
17 & JPM & JPMorgan Chase & Banking & $1991-05-06$ \\
18 & KO & Coca-Cola & Beverages & $1987-03-12$ \\
19 & MCD & McDonald's & Restaurants \& bars & $1985-10-30$ \\
20 & MMM & 3M & Diversified industrials & $1976-08-09$ \\
21 & MO & Altria Group & Cigarettes & $1985-10-30$ \\
22 & MRK & Merck & Pharmaceuticals & $1979-06-29$ \\
23 & MSFT & Microsoft & Software & $1999-11-01$ \\
24 & PFE & Pfizer & Pharmaceuticals & $2004-04-08$ \\
25 & PG & Procter \& Gamble & Non-durable household products & $1932-05-26$ \\
26 & T & AT\&T & Telecommunication & $1999-11-01$ \\
27 & UTX & United Technologies Corporation & Aerospace, heating/cooling & $1939-03-14$ \\
28 & VZ & Verizon Communications & Telecommunication & $2004-04-08$ \\
29 & WMT & Walmart & Broadline retailers & $1997-03-17$ \\
30 & XOM & Exxon Mobil & Integrated oil \& gas & $1928-10-01$ \\
\hline \hline
\end{tabular}

Note: This table provides the ticker, company name, industry, and the date when added to the index for the 30 constituents of the DJIA as of November 21, 2005.

time the value of the Dow divisor was 0.1249, and thus the index was given by

$$
D J I A_{t}=\frac{1}{0.1249} \sum_{i=1}^{N} P_{i, t}
$$

where $P_{i, t}$ is the price of the $i$ 'th company at time $t$. As the Dow divisor was less than one, the index value was actually larger than the sum of the prices of the components, a fact stemming from the numerous stock splits which have occurred with index constituents throughout the existence of the DJIA.

In Table 2 descriptive statistics are provided for the 30 constituents as well as for the DJIA itself. We use daily raw return from December 30, 1997 to December 27, 2006, for a total of 2246 observations. The assets listed exhibit typical features common to many other financial data. The table shows that for 19 out of the 30 stocks returns are negatively skewed and for all 30 stocks returns are leptokurtic. For some the kurtosis is orders of magnitude 
Table 2: Descriptive statistics for Dow Jones companies

\begin{tabular}{|c|c|c|c|c|c|c|}
\hline Ticker & $\min$ & mean & $\max$ & stddev & skewn & kurt \\
\hline AA & -11.66 & 0.03135 & 13.152 & 2.3054 & 0.24098 & 5.5447 \\
\hline AIG & -11.02 & 0.029612 & 10.46 & 1.9135 & 0.077733 & 6.2767 \\
\hline AXP & -14.614 & 0.043158 & 12.018 & 2.1839 & -0.086318 & 6.3712 \\
\hline BA & -11.532 & 0.044143 & 8.4307 & 1.956 & -0.13626 & 6.3866 \\
\hline CAT & -17.115 & 0.050373 & 16.838 & 2.1603 & 0.062693 & 9.2984 \\
\hline $\mathrm{C}$ & -15.686 & 0.055666 & 10.296 & 2.1275 & -0.20395 & 6.686 \\
\hline DD & -11.695 & 0.0038985 & 9.4125 & 1.892 & 0.062353 & 6.2373 \\
\hline DIS & -20.289 & 0.0068601 & 14.203 & 2.2575 & -0.24388 & 10.4 \\
\hline GE & -11.287 & 0.032381 & 11.743 & 1.8493 & 0.053849 & 6.9385 \\
\hline GM & -15.045 & -0.0017424 & 16.647 & 2.298 & 0.10738 & 6.9799 \\
\hline HD & -33.877 & 0.035111 & 12.128 & 2.3967 & -1.3012 & 23.364 \\
\hline $\mathrm{HON}$ & -19.079 & 0.014932 & 24.852 & 2.3863 & -0.25409 & 15.002 \\
\hline $\mathrm{HPQ}$ & -20.701 & 0.024279 & 18.991 & 2.8403 & -0.062388 & 8.5292 \\
\hline IBM & -16.892 & 0.02721 & 12.366 & 2.0634 & -0.12532 & 10.602 \\
\hline INTC & -24.888 & 0.0064339 & 18.335 & 2.9955 & -0.45827 & 8.8805 \\
\hline JNJ & -17.252 & 0.037201 & 7.8925 & 1.5193 & -0.61117 & 13.253 \\
\hline JPM & -19.977 & 0.030022 & 14.873 & 2.3612 & 0.10734 & 8.67 \\
\hline $\mathrm{KO}$ & -11.072 & -0.0057238 & 9.2162 & 1.6461 & -0.17626 & 7.8956 \\
\hline MCD & -13.716 & 0.033771 & 10.31 & 1.8828 & -0.056628 & 7.396 \\
\hline MMM & -9.3837 & 0.037487 & 10.5 & 1.6286 & 0.19183 & 6.3402 \\
\hline MO & -14.853 & 0.045488 & 14.882 & 2.0627 & -0.19121 & 11.009 \\
\hline MRK & -31.171 & 0.0021853 & 12.251 & 1.9419 & -1.9682 & 35.278 \\
\hline MSFT & -16.958 & 0.036521 & 17.869 & 2.2697 & -0.19865 & 9.3492 \\
\hline PFE & -11.817 & 0.012271 & 9.271 & 1.9887 & -0.30771 & 6.328 \\
\hline PG & -37.658 & 0.029849 & 9.0972 & 1.7905 & -4.3843 & 92.943 \\
\hline $\mathrm{T}$ & -13.538 & 0.01585 & 8.8338 & 2.0324 & -0.082488 & 5.9627 \\
\hline UTX & -33.195 & 0.066822 & 9.3762 & 2.0068 & -2.0997 & 38.005 \\
\hline VZ & -12.609 & 0.013821 & 11.565 & 1.918 & 0.065695 & 6.9257 \\
\hline WMT & -10.26 & 0.043204 & 9.0151 & 1.9876 & 0.14496 & 5.6743 \\
\hline XOM & -8.8397 & 0.048885 & 10.485 & 1.564 & 0.054154 & 5.5619 \\
\hline DJIA & -7.396 & 0.021 & 6.1547 & 1.11 & -0.1239 & 6.6772 \\
\hline
\end{tabular}

This table provides descriptive statistics for the 30 constituents of the DJIA. The sample period is from December 30, 1997, to December 27 , 2006 , for a total of 2246 observations. The bottom line provides the equivalent statistics for the index itself. Results are for raw returns in percentage terms.

larger than that of the Gaussian distribution. This is particularly striking for PG, UTX, and MRK which are also the most negatively skewed. The returns on the index are also highly negatively skewed and leptokurtic. As expected the standard deviation of the index is lower than the individual stock standard deviations showing the diversification effect. Finally, as can be seen in Figure 1 all the unconditional correlations are positive. For some of the return pairs the correlation can reach up to $74 \%$ percent, i.e., between JP Morgan and Citigroup. Some stocks are only slightly correlated with the others, e.g., Altria Group. In general, all the other correlations span from about $20 \%$ to $50 \%$. The average correlation is close to $30 \%$. 


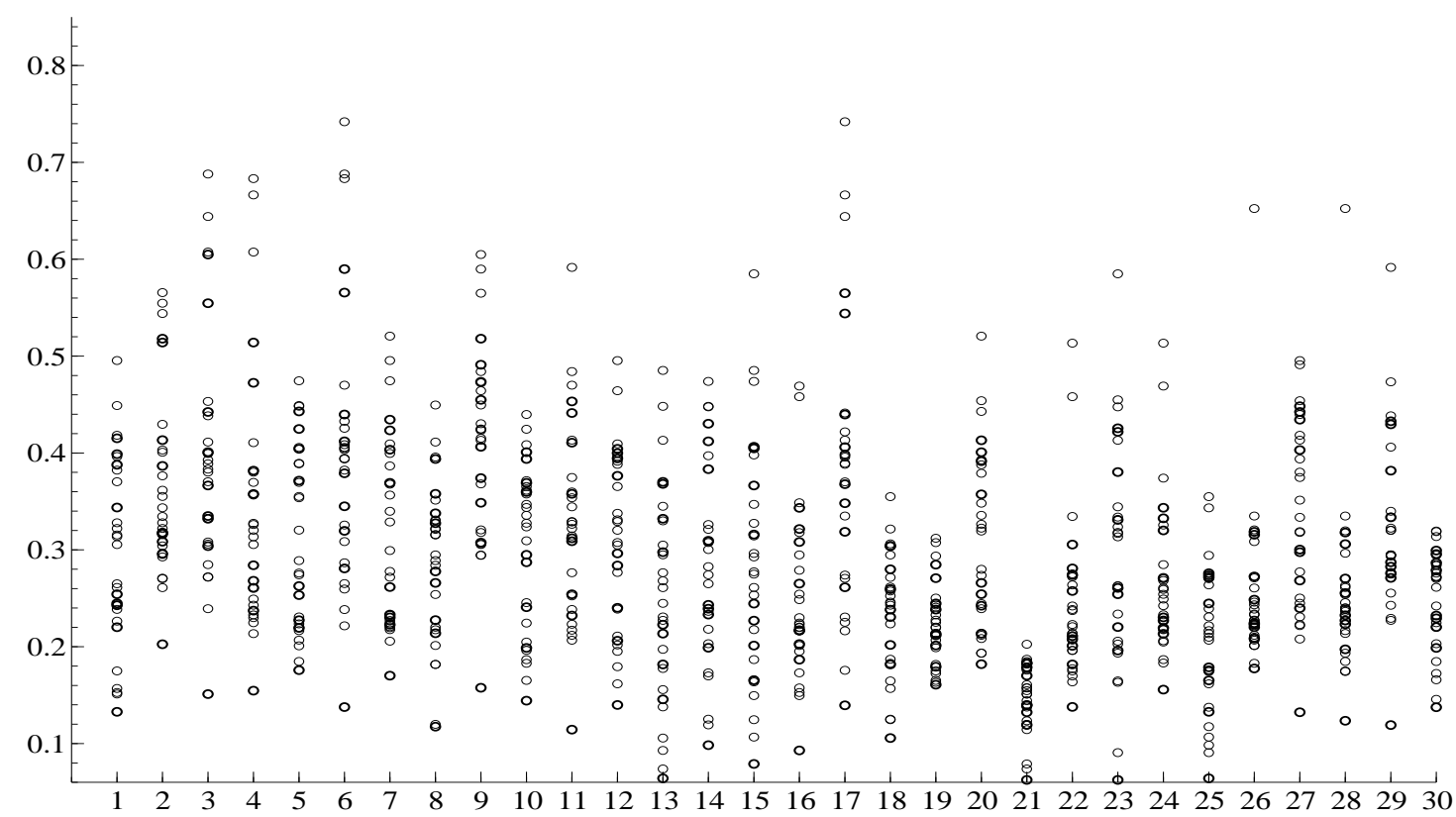

Figure 1: Correlations for each stock with the other DJIA stocks (See Table 1 for the names of the stocks)

\subsection{DJIA option data}

Options on the DJIA were introduced at the Chicago Board of Options Exchange, or CBOE, in 1997. Since this time the options have grown to become some of the most popular index options worldwide. The main reason for this it that investors are able to trade a broad market by making one DJIA trading decision rather than making the many decisions involved with investing in the numerous individual stocks. The DJIA options are European style options and are based on 1/100th of the index level. The options are cash settled and the underlying dollar value is equal to the index level multiplied by $\$ 100$.

In this paper, we consider DJIA call options for 2006. However, since the total number of options traded for 2006 is 54,939 this is clearly too time consuming to deal with and for this reason we apply a number of filters to the sample that are standard in the option pricing literature. First, we only consider options on a weekly basis. This is done to balance the tradeoff between having a long enough time period to be of interest and to have a number of options which is computationally reasonable. Specifically, we choose options traded on 


\section{Table 3: Properties of the DJIA 30 index options data set}

\begin{tabular}{lcccc}
\hline \hline \multicolumn{5}{c}{ Moneyness } \\
& OTM & ITM & DITM & ALL \\
Price & 1.30 & 2.25 & 7.71 & 4.13 \\
number & 406 & 334 & 497 & 1237 \\
\hline
\end{tabular}

Time to maturity in days

\begin{tabular}{lcccc} 
& ST & MT & LT & ALL \\
Price & 4.24 & 3.93 & 4.17 & 4.13 \\
number & 428 & 335 & 474 & 1237 \\
\hline \hline \multicolumn{4}{l}{ Average price in USD and number of call contracts in } \\
the cells of this table. The moneyness and maturity \\
categories are defined in the text.
\end{tabular}

Wednesdays as these are less likely to be affected by the so-called weekend effects. Second, we only consider options which have less than 252 trading days to maturity and, third, options for which the traded volume on a given Wednesday exceeded 5 contracts. Applying these filters yields a sample of 1,237 call options.

In Table 3, we provide descriptive statistics for the options in terms of the number of contracts and their average prices. We tabulate data for various categories of maturity measured in trading days, Mat, and moneyness measured as Mon $=S /\left(K \exp \left(-r_{t} M a t\right)\right)$, where $S$ is the value of the underlying, $K$ is the strike price, and $r_{t}$ is the risk free interest rate. As the risk free rate we use the LIBOR rate which starts at $4.4 \%$ and ends at $5.2 \%$ in 2006 . The moneyness categories are divided into out of the money (OTM), with $M o n<1$, in the money (ITM), with $1 \leq$ Mon $<1.02$, deep in the money (DITM), with $M o n \geq 1.02$. The maturity categories are divided into short term $(\mathrm{ST})$, with $M a t<24$, medium term (MT), with $24 \leq$ Mat $<45$, and long term (LT), with $M a t \geq 45$. The moneyness and maturity categories are defined such that we have roughly the same number of contracts in each category while keeping the definitions meaningful. 


\section{Pricing options on the DJIA}

Letting $\mathcal{F}_{t}$ denote the information set up to time $t$, we assume that the underlying return process $R_{j, t}=\ln \left(P_{j, t} / P_{j, t-1}\right)$ for $j=1, \ldots, N$ can be characterized by

$$
R_{j, t}=\mu_{j, t}-\Psi_{t}\left(-e_{j}\right)+\varepsilon_{j, t}
$$

where $P_{j, t}$ is the price level of asset $j$ on day $t$. The term $\Psi_{t}(\cdot)$ denotes the conditional cumulant generating function of $\varepsilon_{j, t}$, and $e_{j}$ is an $N$ dimensional vector of zeros except for position $j$ where it is 1 . Thus, we have that $\ln \left(E_{t-1}\left[\exp \left(\varepsilon_{j, t}\right)\right]\right)=\Psi_{t}\left(-e_{j}\right)$, and it follows that

$$
\begin{aligned}
E_{t-1}\left[P_{j, t} / P_{j, t-1}\right] & =E_{t-1}\left[\exp \left(\mu_{j, t}-\Psi_{t}\left(-e_{j}\right)+\varepsilon_{j, t}\right)\right] \\
& =\exp \left(\mu_{j, t}\right)
\end{aligned}
$$

The specification in (2) therefore implies that $\mu_{j, t}$ is measurable and can be interpreted as the expected gross rate of return for asset $j$. The error term $\varepsilon_{t}=\left(\varepsilon_{1, t}, \ldots, \varepsilon_{N, t}\right)^{\prime}$ can be decomposed as

$$
\varepsilon_{t}=\Sigma_{t}^{1 / 2} \eta_{t}
$$

The innovation term $\eta_{t}$ in (4) is identically and independently distributed with a $N$-variate absolutely continuous distribution function $F$ (i.e. the physical measure) with first two moments respectively equal to $\mathrm{E}\left[\eta_{t}\right]=0$ and $\mathrm{E}\left[\eta_{t} \eta_{t}^{\prime}\right]=I_{N}$. The latter assumption makes $\Sigma_{t}$ the conditional variance matrix of $\varepsilon_{t}$. Various specifications for this volatility matrix will be provided below in Section 3.3.

In the next section, we make two choices about the innovation distribution and explain how risk neutralization is performed. We then discuss how, by using a simple specification for the rate of return, estimation can be made easier. Finally, we explain how, based on the derived dynamics, options can be priced using Monte Carlo simulation.

\subsection{Risk neutralization}

To perform option pricing, we need the risk neutral dynamics, i.e. the dynamics under $Q$. Rombouts and Stentoft (2011) show that, building on Christoffersen, Elkamhi, Feunou, and 
Jacobs (2010), under the risk neutral measure the conditional cumulant generating function of $\varepsilon_{t}$ is given by

$$
\Psi_{t}^{Q}(u)=\Psi_{t}\left(\nu_{t}+u\right)-\Psi_{t}\left(\nu_{t}\right)
$$

where $\nu_{t}$ is a $N$-dimensional vector sequence. In fact, by using a multivariate generalization of the exponential affine Radon-Nikodym derivative, this provides a unique equivalent martingale measure if and only if

$$
0=\Psi_{t}\left(\nu_{t}-e_{j}\right)-\Psi_{t}\left(\nu_{t}\right)-\Psi_{t}\left(-e_{j}\right)+\mu_{j, t}-r_{t},
$$

for all $j=1, \ldots, N$.

More concretely, in this paper we consider two distributional assumptions, the multivariate Gaussian distribution and the fatter tailed multivariate Laplace distribution. When $F$ is the multivariate Gaussian distribution, the conditional Laplace transform of $\varepsilon_{t}$ in (4) is given by

$$
\mathrm{E}_{t-1} \exp \left(-u^{\prime} \varepsilon_{t}\right)=\exp \left(\frac{u^{\prime} \Sigma_{t} u}{2}\right)
$$

and therefore given (5) we obtain

$$
\begin{aligned}
\Psi_{t}^{Q}(u) & =\Psi_{t}\left(\nu_{t}+u\right)-\Psi_{t}\left(\nu_{t}\right) \\
& =\frac{1}{2}\left(\nu_{t}+u\right)^{\prime} \Sigma_{t}\left(\nu_{t}+u\right)-\frac{1}{2} \nu_{t}^{\prime} \Sigma_{t} \nu_{t} \\
& =u^{\prime} \Sigma_{t}(\theta) \nu_{t}+\frac{1}{2} u^{\prime} \Sigma_{t} u
\end{aligned}
$$

Thus, it follows that the risk neutral dynamics remain Gaussian although with a shifted mean. This shift in the mean is required to compensate investors for the risk associated with investing in the underlying risky assets.

Under the Gaussian assumption we may further solve (6) directly for any specification of $\mu_{j, t}$. This can be done by substituting (7) into (6) upon which we obtain the following

$$
\begin{aligned}
0 & =\frac{1}{2}\left[\left(\nu_{t}-e_{j}\right)^{\prime} \Sigma_{t}\left(\nu_{t}-e_{j}\right)-\nu_{t}^{\prime} \Sigma_{t} \nu_{t}-e_{j}^{\prime} \Sigma_{t} e_{j}\right]+\mu_{j, t}-r_{t} \\
& =-e_{j} \Sigma_{t} \nu_{t}+\mu_{j, t}-r_{t}
\end{aligned}
$$

for all $j=1, \ldots N$. Solving for $\nu_{t}$ we obtain

$$
\nu_{t}=\Sigma_{t}^{-1}\left(\mu_{t}-r_{t}\right)
$$


where $\mu_{t}$ and $r_{t}$ are the corresponding vectors of the gross rate of return and the risk-free interest rate respectively.

The risk neutralization under the multivariate Laplace distribution can be approximated by the one under the Gaussian distribution. To see this, note that the conditional cumulant generating function of the (zero mean) multivariate Laplace distribution, see Eltoft (2006), is given by

$$
\Psi_{t}(u)=-\log \left(1-\frac{u^{\prime} \Sigma_{t} u}{2}\right) .
$$

If we consider the first order Tailor expansion of $\log \left(1-\frac{\left.u^{\prime} \Sigma_{t} u\right)}{2}\right)$ around 1 , then we obtain

$$
\Psi_{t}(u) \approx \frac{u^{\prime} \Sigma_{t} u}{2}
$$

which is indeed consistent with the (zero mean) multivariate Gaussian cumulant generating function. Therefore, while we can apply the same risk neutralization under both distributional assumptions, the multivariate Laplace distribution will generate fatter tails in the predicted future price distribution.

\subsection{Rate of return specification}

To simplify matters further, we make the assumption that the conditional gross rate of return is given as

$$
\mu_{t}=r_{t}+\Sigma_{t} \odot I_{N} \lambda
$$

This means that the risk premium for asset $j$ only depends on the variance of the asset and as a function of this it remains constant through time, i.e. $\lambda_{j}$ is constant. Compared to a more general specification this has the effect of making estimation easier as this can be done for each asset individually.

The particular choice of conditional mean also implies that the risk neutral dynamics are simple. To see this, substitute (9) and the mean specification into (8) to obtain

$$
\Psi_{t}^{Q}(u)=u^{\prime} \Sigma_{t} \odot I_{N} \lambda+\frac{1}{2} u^{\prime} \Sigma_{t} u .
$$

Thus, for this particular choice the risk neutral mean equals $-\Sigma_{t} \odot I_{N} \lambda$, which is readily interpreted as the compensation an investor requires for holding risky assets. Moreover, from the specification it makes sense to refer to $\lambda$ as the price of risk. Finally, it should be noted that we assume for simplicity that interest rates are constant. 
Table 4: Models for the conditional correlations

\begin{tabular}{|c|c|c|}
\hline \multicolumn{3}{|c|}{$\begin{array}{c}\Sigma_{t}=\left(\Sigma_{t} \odot I_{N}\right)^{1 / 2} R_{t}\left(\Sigma_{t} \odot I_{N}\right)^{1 / 2} \\
\left.\text { Cor }_{t}=\left(Q_{t} \odot I_{N}\right)^{-1 / 2} Q_{t}\left(Q_{t} \odot I_{N}\right)^{-1 / 2}\right)\end{array}$} \\
\hline $\mathrm{CCC}$ & $Q_{t}=\bar{Q}$ & Bollerslev (1990) \\
\hline DCC & $Q_{t}=(1-\alpha-\beta) \bar{Q}+\alpha\left(u_{t-1} u_{t-1}^{\prime}\right)+\beta Q_{t-1}$ & Engle (2002) \\
\hline DDCC & $Q_{t}=(1-\beta) \bar{Q}-A \bar{Q} A^{\prime}+A u_{t-1} u_{t-1}^{\prime} A^{\prime}+\beta Q_{t-1}$ & Cappiello et al. (2006) \\
\hline $\mathrm{ADCC}$ & $\begin{aligned} Q_{t}= & (1-\alpha-\beta) \bar{Q}-\Gamma \bar{U} \Gamma^{\prime}+\alpha\left(u_{t-1} u_{t-1}^{\prime}\right)+\beta Q_{t-1}+ \\
& +\Gamma\left(u_{t-1} u_{t-1}^{\prime} \odot 1_{u_{t-1}<0} 1_{u_{t-1}<0}^{\prime}\right) \Gamma^{\prime}\end{aligned}$ & Cappiello et al. (2006) \\
\hline & $\begin{array}{c}\bar{Q}=E\left[u_{t-1} u_{t-1}^{\prime}\right] \\
\bar{U}=E\left[u_{t-1} u_{t-1}^{\prime} \odot 1_{u_{t-1}<0} 1_{u_{t-1}<0}^{\prime}\right] \\
u_{i, t}=\epsilon_{i, t} / h_{i, t}\end{array}$ & \\
\hline
\end{tabular}

\subsection{Volatility models}

We now define the various multivariate GARCH models that will be applied to the $N=30$ stocks in the DJIA. If we define $R_{t}=\left(R_{1, t}, \ldots, R_{N, t}\right)^{\prime}$ then given the above discussion on risk neutralization the econometric model can be written as

$$
\begin{aligned}
R_{t} & =r_{t}+\left(\Sigma_{m, t} \odot I_{N}\right) \lambda-\frac{1}{2}\left(\Sigma_{m, t} \odot I_{N}\right)+\epsilon_{t} \\
\epsilon_{t} & =\Sigma_{m, t}^{1 / 2} \eta_{t},
\end{aligned}
$$

where $\Sigma_{m, t}$ defines the conditional variance matrix for model specification $m$. To make estimation of this 30 dimensional model feasible, the number of parameters being easily higher than 100 in our setting, we consider only models for which the conditional variance matrix can be decomposed as follows

$$
\Sigma_{m, t}=\left(\Sigma_{m, t} \odot I_{N}\right)^{1 / 2} \operatorname{Cor}_{m, t}\left(\Sigma_{m, t} \odot I_{N}\right)^{1 / 2},
$$

where the first part, $\left(\Sigma_{m, t} \odot I_{N}\right)^{1 / 2}$, contains the $N$ conditional standard deviations on the diagonal and where $\operatorname{Cor}_{m, t}$ is the conditional correlation matrix.

We consider four specifications for the conditional correlation matrix, see Table 4, ranging from constant correlations to dynamic correlations that take into account an asymmetry effect. With respect to the models for the marginal variances $h_{t}$, we consider most of the models in the (extensive) glossary of Bollerslev (2010). Since the number of models amounts to 34, see Table 5, we decide to group them by common characteristics. This approach allows us to 
appreciate the value of model sophistication in a concise manner. We distinguish models in five ways: i) linearity in $\epsilon_{t}^{2}$, ii) symmetry related to impact of shocks, iii) direct specification of conditional variance, iv) constant parameters, and v) component type of specifications. More details are given in Table 6.

With respect to the estimation of the model parameters, the specification given in (13) is particularly appealing because it does not include spill over terms in the conditional mean and thus it allows for the factorization of the likelihood as suggested in Engle (2002). In fact, under Gaussianity of the innovations in (13) the total log-likelihood can be decomposed in the sum of the log-likelihoods of the marginal densities and the (multivariate) log-likelihood of the joint density of the centered devolatilized returns. Thus, the estimation can be carried out in two steps: first, the first two conditional moments of the marginal processes and second, the correlation dynamics of the joint process. Further, in order to ease the computational burden of the likelihood of the correlation driving process, we replace $\bar{Q}$ and $\bar{U}$ by the unconditional second moment of $u_{t}$ and $u_{t} \odot 1_{u_{t}<1}$ respectively, see Engle and Mezrich (1995), which saves 465 parameters. Note also that, imposing conditional Gaussianity to all models allows for a quasi maximum likelihood interpretation of the two step estimator independently of the assumed distribution (Gaussian or Laplace).

The models are estimated using data from December 31, 1997 to December 30, 2005 which amounts to 2000 observations, results are too numerous to report but are available on request. To keep computation time reasonable, the parameter estimates are kept fixed over the 52 weeks for which we price option contracts in 2006. In fact, this is also the reason why we consider one year of options. It takes roughly one day on one processor to estimate and price options for each of the 272 model specifications. Due to lack of accuracy in the numerical optimization during the parameter estimation, 24 specifications involving combinations of Alt-garch, sqrt-garch and vgarch have been excluded from the analysis.

\subsection{Option pricing}

The theoretical value at time $t$ of the European call option with a strike price equal to $K$ and maturity in $T$ days is

$$
C_{t}(T, K)=e^{-r_{t}(T-t)} \mathrm{E}_{t}^{Q}\left[\max \left(K-S_{T}, 0\right)\right]
$$


Table 5: Models for the conditional variance

\begin{tabular}{|c|c|c|}
\hline Garch & $h_{t}=\beta_{0}+\beta_{1} \epsilon_{t-1}^{2}+\beta_{2} h_{t-1}$ & Bollerslev, 1986 \\
\hline GJR & $h_{t}=\beta_{0}+\beta_{1} \epsilon_{t-1}^{2}+\beta_{2} \epsilon_{t-1}^{2} 1_{\epsilon_{t-1}<0}+\beta_{3} h_{t-1}$ & Glosten et al, 1993 \\
\hline Alt-Garch & $h_{t}=\beta_{0}+\beta_{1}\left(\epsilon_{t-1}^{2} / h_{t-1}\right)+\beta_{2} h_{t-1}$ & Knight and Satchell, 2002 \\
\hline$\beta$-Garch & $h_{t}=\beta_{0}+\left(\beta_{1} 1_{\epsilon_{t-1}>0}+\beta_{2} 1_{\epsilon_{t-1}<0}\right) \epsilon_{t-1}^{2 \beta_{4}}+\beta_{3} h_{t-1}$ & Guegan and Diebolt, 1994 \\
\hline $\operatorname{Agarch}(\mathrm{a})$ & $h_{t}=\beta_{0}+\beta_{1} \epsilon_{t-1}^{2}+\beta_{2} \epsilon_{t-1}+\beta_{3} h_{t-1}$ & Engle, 1990 \\
\hline $\operatorname{Agarch}(b)$ & $h_{t}=\beta_{0}+\beta_{1}\left|\epsilon_{t-1}\right|^{\beta_{4}}+\beta_{2} \epsilon_{t-1}+\beta_{3} h_{t-1}$ & Engle, 1990 \\
\hline Nagarch & $h_{t}=\beta_{0}+\beta_{1}\left(\epsilon_{t-1}+\beta_{2} \sqrt{h_{t-1}}\right)^{2}+\beta_{3} h_{t-1}$ & Engle and $\mathrm{Ng}, 1993$ \\
\hline Vgarch & $h_{t}=\beta_{0}+\beta_{1}\left(\epsilon_{t-1} / \sqrt{h_{t-1}}+\beta_{2}\right)^{2}+\beta_{3} h_{t-1}$ & Engle and $\mathrm{Ng}, 1993$ \\
\hline$\sqrt{-G a r c h}$ & $h_{t}=\beta_{0}+\beta_{1}\left(\epsilon_{t-1} / \sqrt{h_{t-1}}+\beta_{2} \sqrt{h_{t-1}}\right)^{2}+\beta_{3} h_{t-1}$ & Heston and Nandi, 2000 \\
\hline Vsarch(a) & $h_{t}=\beta_{0}+\beta_{1} \epsilon_{t-1}^{2}+\beta_{2}\left(\epsilon_{t-1}^{2} / h_{t-1}\right) 1_{\epsilon_{t-1}>0}$ & Fornori ond Molo 1005 \\
\hline Vsarch(b) & $\begin{array}{l}\quad-\beta_{2}\left(\epsilon_{t-1}^{2} / h_{t-1}\right) 1_{\epsilon_{t-1}<0}+\beta_{3} h_{t-1} \\
h_{t}=\beta_{0}+\beta_{1} \epsilon_{t-1}^{2}+\beta_{2}\left(\epsilon_{t-1}^{2} / h_{t-1}\right) 1_{\epsilon_{t-1}<0}+\beta_{3} h_{t-1}\end{array}$ & $\begin{array}{l}\text { Fornari and Mele, } 1995 \\
\text { Fornari and Mele } 1995\end{array}$ \\
\hline $\operatorname{Vsarch}(\mathrm{c})$ & $\begin{aligned} h_{t}= & \beta_{0}+\beta_{1} \epsilon_{t-1}^{2}+\beta_{2} h_{t-1}+\beta_{3} \epsilon_{t-1}^{2} 1_{\epsilon_{t-1}>0}-\beta_{3} \epsilon_{t-1}^{2} 1_{\epsilon_{t-1}<0} \\
& +\beta_{4}\left(\epsilon_{t-1}^{2} / h_{t-1}-\beta_{5}\right) 1_{\epsilon_{t-1}>0}-\beta_{4}\left(\epsilon_{t-1}^{2} / h_{t-1}-\beta_{5}\right) 1_{\epsilon_{t-1}<0}\end{aligned}$ & Fornari and Mele, 1996 \\
\hline $\operatorname{Narch}(\mathrm{a})$ & $h_{t}=\beta_{0}+\beta_{1}\left|\epsilon_{t-1}\right|^{\beta_{3}}+\beta_{2} h_{t-1}$ & Engle and Bollerslev, 1986 \\
\hline $\operatorname{Narch}(b)$ & $h_{t}^{\beta_{4} / 2}=\beta_{0}+\beta_{1}\left|\epsilon_{t-1}\right|^{\beta_{4}}+h_{t-1}^{\beta_{4} / 2}$ & Higgins and Bera, 1992 \\
\hline Aparch & $h_{t}^{\beta_{5} / 2}=\beta_{0}+\beta_{1}\left(\left|\epsilon_{t-1}\right|-\beta_{3} \epsilon_{t-1}\right)^{\beta_{5}}+\beta_{4} h_{t-1}^{\beta_{5} / 2}$ & Ding et al, 1993 \\
\hline Hgarch & $h_{t}^{\beta_{6} / 2}=\beta_{0}+\beta_{1} \beta_{6} h_{t-1}^{\beta_{6} / 2}\left(\left|\epsilon_{t-1} /\left(\sqrt{h_{t-1}}\right)\right|-\beta_{2}\right)$ & \\
\hline & $-\beta_{3}\left(\epsilon_{t-1} /\left(\sqrt{h_{t-1}}-\beta_{2}\right)^{\beta_{5}}+\beta_{4} h_{t-1}^{\beta_{6} / 2}\right.$ & Hentschel, 1995 \\
\hline Atgarch & $\sqrt{h_{t}}=\beta_{0}+\beta_{1}\left|\epsilon_{t-1}\right| 1_{\epsilon_{t-1}<0}+\beta_{2}\left|\epsilon_{t-1}\right| 1_{\epsilon_{t-1}>0}+\beta_{3} \sqrt{h_{t-1}}$ & Crouhy and Rokinger, 1997 \\
\hline Tarch & $\sqrt{h_{t}}=\beta_{0}+\beta_{1}\left|\epsilon_{t-1}\right|+\beta_{2}\left|\epsilon_{t-1}\right| 1_{\epsilon_{t-1}<0}+\beta_{3} \sqrt{h_{t-1}}$ & Zakoian, 1990 \\
\hline TS-Garch & $\sqrt{h_{t}}=\beta_{0}+\beta_{1}\left|\epsilon_{t-1}\right|+\beta_{2} \sqrt{h_{t-1}}$ & Taylor and Schwert, 1989 \\
\hline $\log$-Garch & $\log \left(h_{t}\right)=\beta_{0}+\beta_{1} \log \left(\epsilon_{t-1}^{2}\right)+\beta_{2} \log \left(h_{t-1}\right)$ & Geweke, 1986, Pantula, 1986 \\
\hline Egarch & $\log \left(h_{t}\right)=\beta_{0}+\beta_{1}\left(\epsilon_{t-1} / h_{t-1}\right)$ & \\
\hline & $+\beta_{2}\left(\left|\epsilon_{t-1} / h_{t-1}\right|-\sqrt{2 / \pi}\right)+\beta_{3} \log \left(h_{t-1}\right)$ & Nelson,1990 \\
\hline March & $\begin{array}{l}h_{t}=\beta_{0}+\beta_{1} F\left(\epsilon_{t-1}\right)+\beta_{2} h_{t-1} \\
F\left(\epsilon_{t}\right)=\sin \left(\beta_{3} \epsilon_{t}^{2}\right) 1_{\beta_{3} \epsilon_{t}^{2}<\pi / 2}+1_{\beta_{3} \epsilon_{t}^{2}>\pi / 2}\end{array}$ & Friedman et al, 1989 \\
\hline ST-Garch & $h_{t}=\beta_{0}+\left(\beta_{1}+\beta_{2} F\left(\epsilon_{t-1}\right)\right) \epsilon_{t-1}^{2}+\beta_{3} h_{t-1}$ & \\
\hline LST & $F\left(\epsilon_{t}\right)=\left(1+\exp \left(-\beta_{4} \epsilon_{t}\right)\right)^{-1}-0.5$ & Gonzalez-Rivera, 1998 \\
\hline EST & $F\left(\epsilon_{t}\right)=\left(1-\exp \left(-\beta_{4} \epsilon_{t}^{2}\right)\right)$ & Hagerud, 1996 \\
\hline GLST & $F\left(\epsilon_{t}\right)=\left(1-\exp \left(-\beta_{4} \epsilon_{t}^{2}\right)\right) /\left(1+\exp \left(-\beta_{4}\left(\epsilon_{t}^{2}-\beta_{5}\right)\right)\right)$ & Lubrano, 1998 \\
\hline GEST & $F\left(\epsilon_{t}\right)=\left(1-\exp \left(-\beta_{4}\left(\epsilon_{t}-\beta_{5}\right)^{2}\right)\right)$ & Lubrano, 1998 \\
\hline ANST-Garch & $\begin{array}{l}h_{t}=\beta_{0}+\beta_{1} \epsilon_{t-1}^{2}+\beta_{2} h_{t-1}+\left(\beta_{3}+\beta_{4} \epsilon_{t-1}^{2}+\beta_{5} h_{t-1}\right) F\left(\epsilon_{t-1}\right) \\
F\left(\epsilon_{t}\right)=\left(1+\exp \left(-\beta_{6} \epsilon_{t}\right)\right)^{-1}\end{array}$ & Nam et al, 2002 \\
\hline Cgarch & $\begin{array}{l}h_{t}=q_{t}+\beta_{3}\left(\epsilon_{t-1}^{2}-q_{t-1}\right)+\beta_{4}\left(h_{t-1}-q_{t-1}\right) \\
q_{t}=\beta_{0}+\beta_{1}\left(\epsilon_{t-1}^{2}-h_{t-1}\right)+\beta_{2} q_{t-1}\end{array}$ & Engle and Lee, 1993 \\
\hline Acgarch & $\begin{aligned} h_{t}= & q_{t}+\beta_{4}\left(\epsilon_{t-1}^{2}-q_{t-1}\right) \\
& +\beta_{5}\left(\epsilon_{t-1}^{2} 1_{\epsilon_{t-1}<0}-0.5 q_{t-1}\right)+\beta_{6}\left(h_{t-1}-q_{t-1}\right) \\
q_{t}= & \beta_{0}+\beta_{1}\left(\epsilon_{t-1}^{2}-h_{t-1}\right) \\
& +\beta_{2}\left(\epsilon_{t-1}^{2} 1_{\epsilon_{t-1}<0}-0.5 h_{t-1}\right)+\beta_{3} q_{t-1}\end{aligned}$ & Engle and Lee, 1993 \\
\hline $2 \mathrm{C}(.) \mathrm{Garch}^{*}$ & $\begin{array}{l}h_{t}=\beta_{4} s_{t}+\left(1-\beta_{4}\right) l_{t} \\
s_{t}=\beta_{1}+\beta_{2} \epsilon_{t-1}^{2}+\beta_{3} s_{t-1} \\
l_{t}=\beta_{0} \epsilon_{t-1}^{2}+\left(1-\beta_{0}\right) l_{t-1}\end{array}$ & Ding and Granger, 1996 \\
\hline
\end{tabular}

\footnotetext{
${ }^{*}$ In the 2C(.)Garch the dynamics of the short term component $s_{t}$ can be replaced by more sophisticated specifications. We consider other than the simple Garch also Tarch and Nagarch. The three specifications are denoted 2C(I)Garch, 2C(I)Tarch and 2C(I)Nagarch, respectively, where the I denotes the integrated Garch (IGarch) specification used for the long term component $l_{t}$. We also consider a different parameterization where the long term component $l_{t}$ is a standard stationary Garch model. The corresponding three specifications are denoted 2C(G)Garch, 2C(G)Tarch and 2C(G)Nagarch, respectively. See Bollerslev (2010) for the exact bibliographic references.
} 
Table 6: Characterizations of conditional variance models

\begin{tabular}{ll}
\hline \hline lin & Garch, Alt-Garch, GJR, Vsarch (a,b,c), 2C(G)-Garch, 2C(I)-Garch, Cgarch, Acgarch \\
non lin & TSgarch, Narch(a,b), March, Egarch, $\beta$-Garch, Tarch, Atgarch, Agarch (a,b), Nagarch \\
& Vgarch, $\sqrt{ }$-Garch, Aparch, Hgarch, LST-Garch, EST-Garch, GLST-Garch, GEST-Garch \\
& ANST-Garch, 2C(I)-Tarch, 2C(G)-Tarch, 2C(I)-Nagarch, 2C(G)-Nagarch \\
\hline sym & Garch, Alt-Garch, TSgarch, Narch(a,b), March, EST-Garch, GLST-Garch \\
& 2C(G)-Garch, 2C(I)-Garch, Cgarch \\
asym & Egarch, GJR, $\beta$-Garch, Atgarch, Tarch, Agarch(a,b), Nagarch, Vgarch, V-garch \\
& Aparch, Hgarch, Vsarch(a,b,c), LST-Garch, GEST-Garch, ANST-Garch, 2C(I)-Tarch \\
& 2C(G)-Tarch, 2C(I)-Nagarch, 2C(G)-Nagarch, Acgarch \\
\hline$h_{t}$ & Garch, Alt-Garch, Narch(b), March, GJR, $\beta$-Garch, Agarch(a,b), Nagarch, Vgarch \\
& -Garch, Vsarch(a,b,c), LST-Garch, EST-Garch, GLST-Garch, GEST-Garch, ANST-Garch \\
& 2C(G)-Nagarch, 2C(I)-Nagarch, 2C(G)-Garch, 2C(I)-Garch, Cgarch, Acgarch \\
& TSgarch, Narch(a), Egarch, Tarch, Atgarch, Aparch, Hgarch, 2C(G)-Tarch, 2C(I)-Tarch \\
\hline cst par & Garch, Alt-Garch, TSgarch, Narch(a,b), March, Egarch, Gjr, $\beta$-Garch, Tarch, Atgarch \\
& Agarch(a,b), Nagarch, Vgarch, $\sqrt{ }$-Garch, Aparch, Hgarch, Vsarch(a,b,c), 2C(G)-Garch \\
& 2C(I)-Garch, 2C(G)-Tarch, 2C(I)-Tarch, 2C(G)-Nagarch, 2C(I)-Nagarch, Cgarch, Acgarch \\
st & EST-Garch, GLST-Garch, LST-Garch, GEST-Garch, ANST-Garch \\
\hline std & Garch, Alt-garch, TSgarch, Narch(a,b), March, Egarch, GJR, $\beta$-Garch, Tarch, Atgarch \\
& Agarch(a,b), Nagarch, Vgarch, $\sqrt{ }$-Garch, Aparch, Hgarch, Vsarch(a,b,c), LST-garch \\
& EST-Garch, GLST-Garch, GEST-Garch, ANST-Garch \\
& 2C(I)-Garch, 2C(G)-Garch, 2C(I)-Tarch, 2C(G)-Tarch, 2C(I)-Nagarch, 2C(G)-Nagarch \\
& Cgarch, Acgarch
\end{tabular}

Notes: lin (non lin): models linear (non linear) in $\epsilon_{t}^{2}$, sym (asym): models with symmetric (asymmetric) impact of shocks wrt the sign of the shock, $h_{t}\left(f\left(h_{t}\right)\right)$ : models where the variance (a function of the variance) is explicitly modelled, cst (st): models with constant parameters (smooth transition), std (comp): single component (2-component). The total number of specifications is 34. Categories in each pair are mutually exclusive. See Table 5 for the precise functional forms. 
where $\mathrm{E}_{t}^{Q}$ means that the expectation is taken under the risk neutral measure $Q$ and where $S_{T}$ is the value at time $T$ of the underlying index. While closed form solutions to (15) do exist in a few cases, i.e. the constant volatility Gaussian case, this is not so for more general specifications of the underlying dynamics. However, even in this case it remains possible to price the options using numerical methods.

We use a Monte Carlo approach which is easy to implement in the current setting as the models are simple to simulate from under the risk neutral distribution. The use of Monte Carlo methods for option pricing goes back at least to Boyle (1977). For the European option example in (15), given initial values of $P_{t}, r_{t}, \Sigma_{t}$, and the parameter estimates of a model, we simulate $B$ paths of length $T-t$ for the return process under the risk neutral measure. More precisely

$$
\begin{aligned}
R_{t+i}^{(b)} & =\mu_{t+i}-\frac{1}{2} \Sigma_{t+i}^{(b)} \odot I_{N}+\varepsilon_{t+i}^{(b)} \\
\varepsilon_{t+i}^{(b)} & =-\Sigma_{t+i}^{(b)} \odot I_{N} \hat{\lambda}+\Sigma_{t+i}^{1 / 2(b)} \eta_{t+i}^{(b)} \\
\mu_{t+i} & =r_{t+i \mid t}+\Sigma_{t+i}^{(b)} \odot I_{N} \hat{\lambda},
\end{aligned}
$$

where $\eta_{t+i}^{(b)} \sim F\left(0, I_{N}\right)$ with $F$ either the Gaussian or Laplace distribution, $b=1, \ldots, B$ denotes the number of paths chosen to be sufficiently large (fixed to 20,000 in the application), and $r_{t+i \mid t}$ is the conditional expectation of the risk free rate which is assumed fixed and equal to $r_{t}$. Given each return path, we compute the predicted price of each stock at maturity as

$$
P_{T}^{(b)}=P_{t} \exp \left(\sum_{i=1}^{T-t} R_{t+i}^{(b)}\right),
$$

and the index $S_{T}^{(b)}$ using (1). Then, an estimate of the price of a call option is given by

$$
\hat{C}_{t}(T, K)=e^{-r_{t}(T-t)} \frac{1}{B} \sum_{b=1}^{B} \max \left(K-S_{T}^{(b)}, 0\right),
$$

where $S_{T}^{(b)}$ is the terminal index value simulated under the risk neutral dynamics for the $b$ th path. More generally, the advantages of generating the multivariate price paths is that it can be used in any dimension and consequently any type of derivative contract on the underlying assets can be priced. In addition, with a Monte Carlo approach American options could also be priced using e.g. the Least-Squares Monte Carlo method of Longstaff and Schwartz (2001), for which the mathematical foundation was provided in Stentoft (2004). 


\section{Evaluating option pricing models}

We start by explaining which loss functions we use to contrast predicted option prices to their realizations. Next, we investigate the pricing accuracy of the models (distinguished by similar characteristics for the marginal variances, type of correlations, and innovation distribution) for all options, and then we repeat the analysis for the different categories of moneyness and maturity. Finally, we provide inference, using the model confidence set approach, on predictive accuracy of each individual model in order to identify the set of superior models.

\subsection{Evaluation criteria}

We will analyze the pricing performance of the models measured in dollar losses. The predicted option prices are contrasted with the observed option prices using the mean absolute deviation, or MAD, loss and mean absolute relative deviation, or MARD, loss which measures the deviation in percentage points. The two loss functions are respectively defined as $W^{-1} \sum_{n}^{W}\left|C_{n}-\hat{C}_{n}\right|$ and $W^{-1} \sum_{n=1}^{W}\left|\frac{C_{n}}{\hat{C}_{n}}-1\right|$ where $W$ is the number of options considered. Figure 2 visualizes the difference between loss functions.

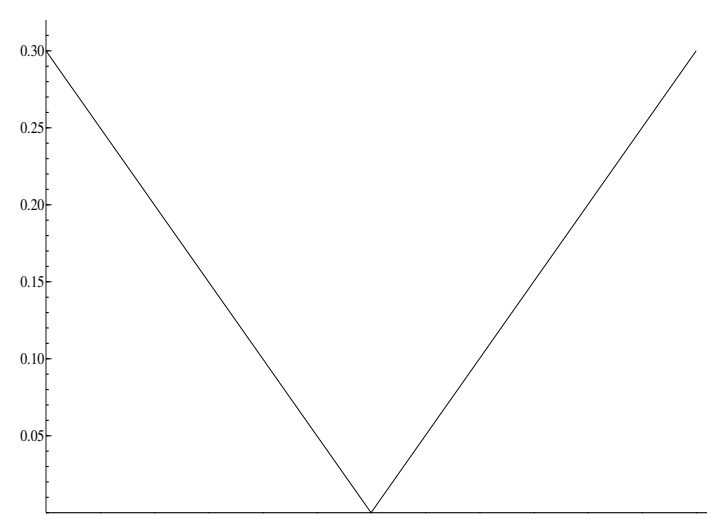

(a) $L\left(C_{n}, \hat{C}_{n}\right)=\frac{1}{W} \sum_{n=1}^{W}\left|C_{n}-\hat{C}_{n}\right|$

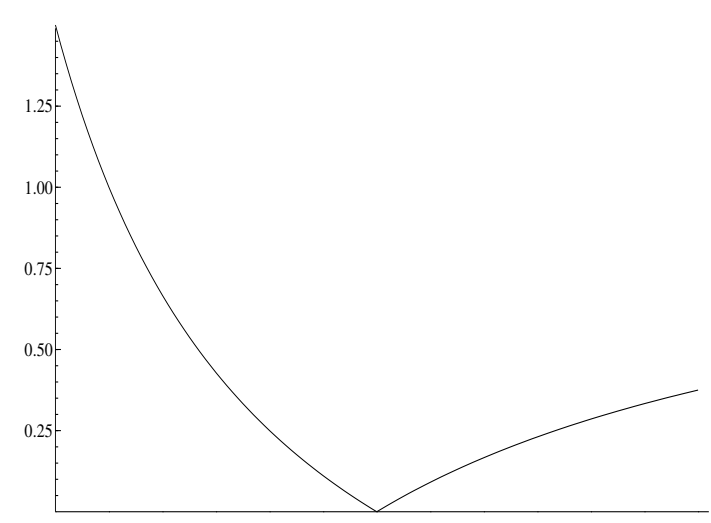

(b) $L\left(C_{n}, \hat{C}_{n}\right)=\frac{1}{W} \sum_{n=1}^{W}\left|\frac{C_{n}}{C_{n}}-1\right|$

Figure 2: MAD (left) - MARD (right)

The choice of these loss functions is not coincidental. In fact, the MAD loss function interprets the pricing accuracy in average dollar losses and is symmetric in the sense that over and under predictions are penalized equally. The MARD loss function measures deviations in percentage terms in a unit free way, and as can be seen from Figure 2 is slightly asymmetric, 
assigning heavier weights to underpredictions.

\subsection{Overall results}

Table 7 summarizes the results for the variance model groups identified in Table 6 for each correlation specification and choice of innovation distribution. The evaluation is based on the MAD loss for each of these categories. For space considerations, the results for the MARD loss function are found in Appendix 1 and will be commented only briefly.

With respect to the contribution of the marginal variance specification to the pricing accuracy, we find that modelling nonlinearity, asymmetry and functional transformations of the conditional variance yields systematic economic gains. Christoffersen and Jacobs (2004) and Stentoft (2005) also find empirically that nonlinearities and asymmetries are important in univariate option pricing models. Also in line with recent literature, see e.g. Christoffersen, Jacobs, Ornthanalai, and Wang (2008), we find that the largest gains are obtained when moving from a standard single component to a two component approach where the conditional variance is expressed as a linear combination of a long term (typically slow moving) component and a short term one. When comparing these two modelling approaches, for a given correlation specification and innovation distribution we obtain gains of up to $45 \%$. However, increasing model sophistication does not always pay off. This is the case for smooth transition models which are systematically and largely outperformed by simpler specifications.

If we focus on the contribution of increasing the model sophistication of the correlation structure, we find that allowing for dynamic correlations produces better price forecasts, though the gains are of a much smaller order of magnitude compared to the marginal variance specifications. For example, moving from constant correlations to dynamic correlations provides gains only up to $3 \%$. Increasing further the complexity of the correlation model provides only marginal, if not negligible, gains. In fact, in the cases of the symmetric marginal variance specification with Gaussian innovations and the component specifications with Laplace innovations the asymmetric correlation specifications perform the worst.

Finally, when comparing the performance for the two choices of innovation distributions, Table 7 shows that pricing with Laplace innovations in general brings considerable gains. Similar findings are reported in Christoffersen, Heston, and Jacobs (2006) and Stentoft (2008) for univariate models. In the multivariate framework presented here, allowing for non-Gaussian 
Table 7: Mean absolute deviation losses in dollars within each class of models

\begin{tabular}{|c|c|c|c|c|c|c|c|c|c|c|}
\hline \multirow{6}{*}{$\begin{array}{l}\text { CCC } \\
\text { DCC } \\
\text { DDCC } \\
\text { ADCC }\end{array}$} & \multicolumn{8}{|c|}{$\begin{array}{l}\text { Panel A: Gaussian innovations } \\
\text { Characteristics of the marginal variances }\end{array}$} & & \\
\hline & lin vs. & non lin & sym vs. & asym & $h_{t}$ vs. & $f\left(h_{t}\right)$ & cst pa & vs. st & std $v$ & comp \\
\hline & 0.533 & 0.529 & 0.588 & 0.501 & 0.539 & 0.508 & 0.518 & 0.598 & 0.570 & 0.398 \\
\hline & 0.527 & 0.521 & 0.581 & 0.494 & 0.5 & 0.4 & 0.5 & 0.5 & & 0.409 \\
\hline & 0.523 & 0.519 & 0.577 & 0.492 & 0.530 & 0.499 & 0.507 & 0.588 & & 0.389 \\
\hline & 0.523 & 0.517 & 0.591 & 0.488 & 0.529 & 0.495 & 0.505 & 0.587 & 0.559 & 0.387 \\
\hline
\end{tabular}

Panel B: Laplace innovations

Characteristics of the marginal variances

\begin{tabular}{lllllllllll} 
& \multicolumn{2}{c}{ lin vs. non lin } & \multicolumn{2}{l}{ sym vs. asym } & \multicolumn{2}{l}{$h_{t}$ vs. $f\left(h_{t}\right)$} & cst par vs. st & std vs. comp \\
CCC & 0.510 & 0.441 & 0.504 & 0.441 & 0.498 & 0.369 & 0.448 & 0.516 & 0.485 & 0.375 \\
DCC & 0.502 & 0.432 & 0.489 & 0.432 & 0.490 & 0.361 & 0.440 & 0.508 & 0.476 & 0.367 \\
DDCC & 0.499 & 0.432 & 0.489 & 0.433 & 0.489 & 0.359 & 0.440 & 0.508 & 0.476 & 0.379 \\
ADCC & 0.497 & 0.428 & 0.486 & 0.430 & 0.486 & 0.355 & 0.437 & 0.505 & 0.472 & 0.379 \\
\hline
\end{tabular}

Note: lin (non lin): models linear (non linear) in $\epsilon_{t}^{2}$, sym (asym): models with symmetric (asymmetric) impact of shocks wrt the sign of the shock, $h_{t}\left(f\left(h_{t}\right)\right)$ : models where the variance (a function of the variance) is explicitly modelled, cst (st): models with constant parameters (smooth transition), std (comp): standard GARCH (component GARCH). See Table 6 for the specific models belonging to each group. With respect to the marginal variance specifications, this table is read by pairwise columns, i.e. each pair identifies two mutually exclusive groups of models aggregated by common characteristics which allows to compare simple specifications (left column) to more complex ones (right column). 
innovations often improves the performance above and beyond that of adding flexibility to the correlation or variance specifications. For example, changing the distribution for linear models with a CCC specification decreases the pricing errors by $0.023 \$$, from $0.533 \$$ to $0.510 \$$, whereas allowing for non linearities in the variance or dynamics and asymmetries in the correlation specification only reduces the pricing errors by $0.006 \$$ and $0.010 \$$, respectively. However, note that once a component structure is used the benefit of allowing for non-Gaussian innovations is marginal. This is in line with Christoffersen, Dorion, Jacobs, and Wang (2010) who find that the generalized error distribution does not improve much on a Gaussian innovation assumption for the component model when valuing options with univariate models.

As suggested above, the specification for the marginal variances plays a dominant role in improving pricing performances, followed by the choice for the distribution and, only marginally by the specification of the correlation dynamics. To this regard, the bubble plot in Figure 3 provides some more specific insights. Each bubble identifies a cluster of correlation models (CCC, DCC, DDCC, ADCC) characterized by the same specifications for the variances of the marginal processes. The bubbles are centered around the within cluster average loss, their diameter is the range computed on the MAD, which is used as a measure of the within cluster dispersion. The horizontal axis represents the MAD and the vertical axis the MARD. Black and grey bubbles identify the models using the Gaussian and Laplace densities respectively.

With respect to the different choice of the marginal variances (Figure 3, top), we see that aggregates of models cover a relatively wide range, from $0.24 \$$ to $0.71 \$$, with a high degree of between models dispersion. Also, at this lower level of aggregation, the potential marginal gains that can be obtained from deviating from the standard Gaussian assumption, for given choice of the variance specification, appear clear. Zooming in on the top of the classification (Figure 3, bottom), we see that, consistently with Tables 7 and 11, the most accurate models all share similar characteristics, i.e., asymmetry, non-linearity, indirectly modelling the variance as a functional transformation, and most relevantly the two component structure. The latter class of models accounts for 7 out of 12 models, with the $2 \mathrm{C}(\mathrm{I})$ Tarch specifications appearing largely superior to the others. Figure 3 (bottom) also allows to measure the contribution of using a fatter tailed distribution. If we consider again the $2 \mathrm{C}(\mathrm{I})$ Tarch spec- 


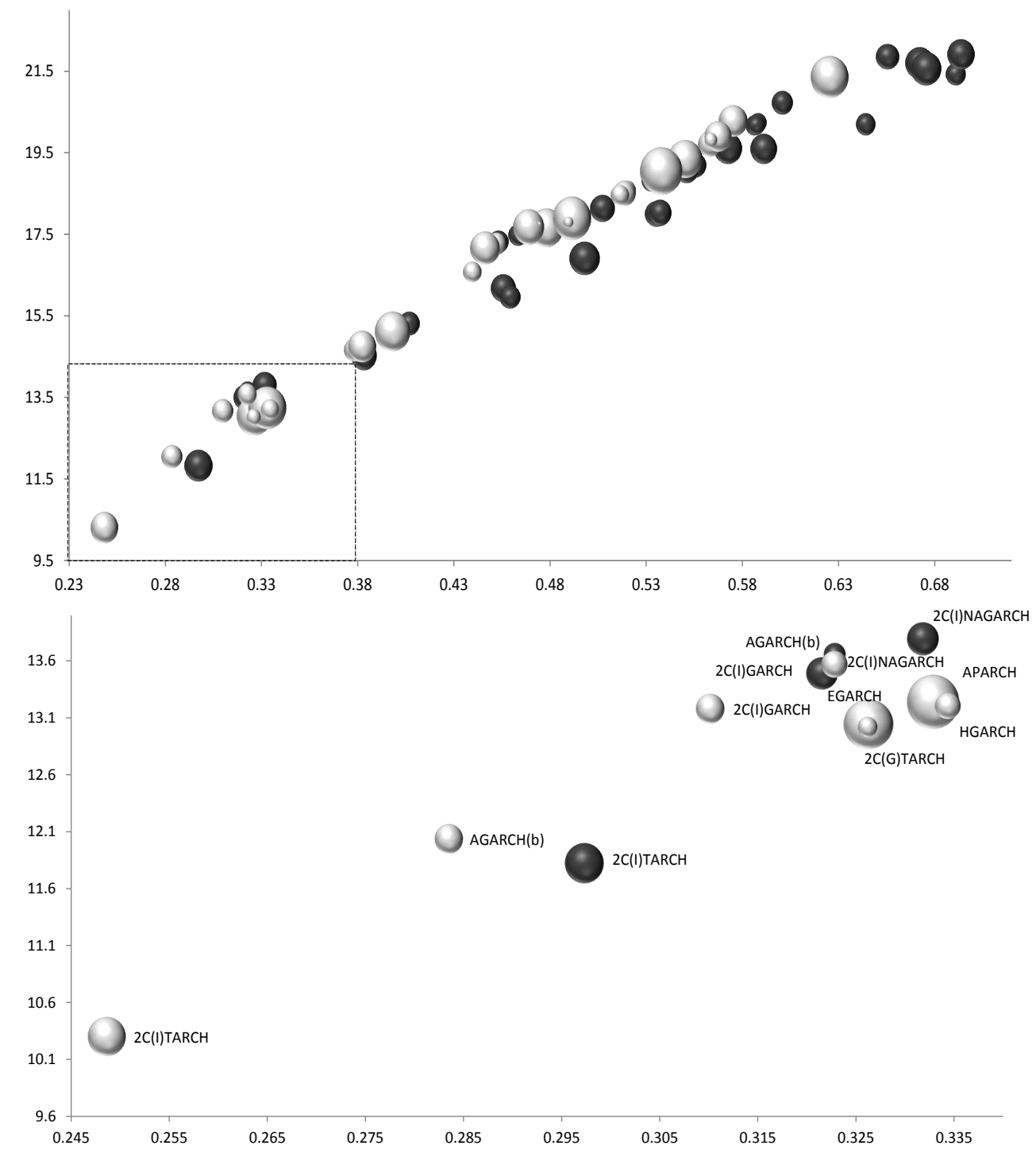

Figure 3: MAD and MARD losses for all options

Note: MAD (x-axis) and MARD (y-axis). Each bubble identifies a group of correlation models (CCC, DCC, DDCC, ADCC) characterized by the same specifications for the variance of the marginal processes. The bubbles are centered around the within group average loss, their diameter is the range computed on the MAD. Black and grey bubbles identify the models using the Gaussian and Laplace densities respectively. The second plot zooms in on the square in the first plot. 
ifications, the models using Laplace conditional density perform about $20 \%$ better than the same specifications using the Gaussian density. The same holds to a similar extent for the other clusters of models.

\subsection{Results across moneyness and maturity}

Table 8 reports MAD losses along the different categories of moneyness as defined in Table 3. The OTM contracts, which have a low average price, are more difficult to price (relative errors spanning from $30 \%$ to $40 \%$ as can be seen in Table 12 of the Appendix) and increasing the complexity of the model still pays off generally. First, with respect to the marginal variances we find again that the largest improvement is for the two component models (up to 55\%) and that the other pairwise categories give less pronounced differences than for all the contracts together. Figure 4 (top) illustrates that indeed the individual models are characterized by substantially different performances. Second, regarding the correlation models it turns out that idiosyncratic dynamics outperforms asymmetry under a Gaussian innovation assumption only. Third, relaxing the Gaussian assumption to the Laplace distribution delivers important gains of larger size than for all the contracts above.

The overall picture of the ITM and DITM options is rather similar to the entire aggregate of options. As can be seen from the bubble plot in Figure 4, the absolute dollar losses are similar to the OTM contracts for good models. It is also clear that increasing the model sophistication of the marginal variances still provides gains, though to a lower extent than what is observed for OTM contracts. The distributional assumption and the choice of the correlation model plays a marginal, if not negligible, role. However, looking solely at the performances of models based on the MAD provides only a partial understanding of the results. In fact, it has to be mentioned that, unlike OTM options, ITM and DITM contracts are characterized by a much higher value (see Table 3). Thus, when the pricing accuracy is measured in terms of relative errors, losses drop into the 11\%-16\% range for ITM options and between $4.5 \%$ and $5.6 \%$ for DITM options, which shows a dramatic increase in the degree of accuracy with respect to the profitability of the category of options. The two component models again show overall the best performances. The performance of less accurate models also improves showing a large reduction in across model variability, hence the value of model sophistication declines rapidly as the moneyness increases. Evidence of this is the very tight 
interval in which all models cluster, in particular, when used to price DITM contracts.

Table 9 reports the MAD losses along the different categories of maturity as defined in Table 3. From this it is clear that short maturity options are much more accurately priced, with errors within the range of $7.4 \%$ and $9.5 \%$, than medium and long term options, with errors in the $8.4 \%-13 \%$ and $20.3 \%-29.8 \%$ range, respectively. With respect to the short maturity options, model sophistication pays off to a lesser extent, and as before more complex marginal variances specifications take the largest share of the potential gains. While there is some gain in allowing for dynamics in the correlation, the simplest common dynamics specification (DCC) seem to be sufficient. Finally, regarding the innovation distribution, deviating from Gaussianity does not yield systematic gains.

As the maturity increases, the choice of an adequate model and thus the value of model sophistication becomes striking. As appears from Figure 4 (bottom), not only performances of all models deteriorate (both in absolute and relative terms) but also the forecasts become less informative (i.e. they converge to their unconditional levels) and model performances become more dispersed.

\subsection{Model confidence sets}

The MCS approach of Hansen, Lunde, and Nason (2011) allows to identify, from an initial set of $M$ models, a subset of forecasts that contains the best forecast at a confidence level $\alpha$. Let us denote the initial set of option price forecasts $\mathcal{M}^{0}:\left\{\hat{C}_{m, n} \in \mathcal{M}^{0} \forall m=1, \ldots, M\right\}$, where $n=1, \ldots, W$ denotes the sequence of option contracts with true price $C_{n}$ and which are considered as a cross-section. The starting hypothesis is that all forecasts in $\mathcal{M}^{0}$ have equal forecasting performance, measured by a loss function $L_{m, n}=L\left(C_{n}, \hat{C}_{m, n}\right)$. Here, $L_{m, n}$ is either the MAD or the MARD loss function as defined in Section 4.1. Let $d_{i j, n}=L_{i, n}-L_{j, n}$ $\forall i, j \in \mathcal{M}^{0}$ define the relative performance of forecast $i$ and $j$ for contract $n$. The null hypothesis takes the form $H_{0, \mathcal{M}^{0}}: E\left(d_{i j, n}\right)=0, \forall i, j=1, \ldots, M$. We use the 'deviation' statistic defined as $T_{D}=M^{-1} \sum_{i \in \mathcal{M}^{0}} t_{i}^{2}$, where $t_{i}=\sqrt{W} \bar{d}_{i} / \sqrt{\operatorname{Var}\left(\sqrt{W} \bar{d}_{i}\right)}$ represents the standardized relative performance of forecast $i$ with respect to the average across forecasts, $\bar{d}_{i}=M^{-1} \Sigma_{j \in \mathcal{M}^{0}} \overline{d_{i j}}$ and $\overline{d_{i j}}=W^{-1} \Sigma_{n=1}^{W} d_{i j, n}$ is the sample loss difference between forecast $i$ and $j$. An i.i.d. bootstrap scheme, producing 10,000 resamples, is used to obtain the distribution under the null. If the null is rejected, an elimination rule removes the forecast with 
Table 8: Absolute deviation losses in dollars by moneyness

\begin{tabular}{|c|c|c|c|c|c|c|c|c|c|c|}
\hline \multicolumn{11}{|c|}{$\begin{array}{c}\text { Panel A: Gaussian innovations } \\
\text { Characteristics of the marginal variances }\end{array}$} \\
\hline \multicolumn{11}{|c|}{$\begin{array}{r}\text { n sym vs. asym } h_{t} \text { vs. } f\left(h_{t}\right) \text { cst par vs } \\
\text { OTM }(406 \text { contracts })\end{array}$} \\
\hline $\mathrm{CCC}$ & 0.779 & 0.777 & 0.893 & 0.720 & 0.794 & 0.740 & 0.753 & 0.900 & 0.846 & 0.555 \\
\hline DCC & 0.770 & 0.767 & 0.884 & 0.712 & 0.784 & 0.729 & 0.744 & 0.891 & 0.836 & 0.572 \\
\hline $\mathrm{DDCC}$ & 0.763 & 0.761 & 0.873 & 0.705 & 0.778 & 0.723 & 0.737 & 0.882 & 0.829 & 0.538 \\
\hline $\mathrm{ADCC}$ & 0.766 & 0.763 & 0.879 & 0.706 & 0.781 & 0.724 & 0.739 & 0.885 & 0.832 & 0.540 \\
\hline \multicolumn{11}{|c|}{ ITM (334 contracts) } \\
\hline $\mathrm{CCC}$ & 0.460 & 0.435 & 0.487 & 0.419 & 0.459 & 0.401 & 0.431 & 0.494 & 0.471 & 0.344 \\
\hline DCC & 0.451 & 0.424 & 0.477 & 0.410 & 0.449 & 0.390 & 0.422 & 0.484 & 0.461 & 0.349 \\
\hline $\mathrm{DDCC}$ & 0.452 & 0.428 & 0.479 & 0.412 & 0.452 & 0.393 & 0.424 & 0.486 & 0.464 & 0.335 \\
\hline $\mathrm{ADCC}$ & 0.445 & 0.420 & 0.473 & 0.404 & 0.445 & 0.385 & 0.416 & 0.479 & 0.457 & 0.329 \\
\hline \multicolumn{11}{|c|}{ DITM (497 contracts) } \\
\hline $\mathrm{CCC}$ & 0.382 & 0.388 & 0.408 & 0.376 & 0.385 & 0.390 & 0.379 & 0.422 & 0.410 & 0.307 \\
\hline DCC & 0.381 & 0.384 & 0.404 & 0.373 & 0.382 & 0.385 & 0.376 & 0.418 & 0.406 & 0.316 \\
\hline DDCC & 0.375 & 0.383 & 0.400 & 0.372 & 0.379 & 0.386 & 0.374 & 0.416 & 0.405 & 0.303 \\
\hline $\mathrm{ADCC}$ & 0.376 & 0.382 & 0.402 & 0.370 & 0.379 & 0.383 & 0.373 & 0.416 & 0.405 & 0.301 \\
\hline
\end{tabular}

Panel B: Laplace innovations

Characteristics of the marginal variances

\begin{tabular}{|c|c|c|c|c|c|c|c|c|c|c|}
\hline \multirow[b]{2}{*}{$\mathrm{CCC}$} & \multicolumn{2}{|c|}{ lin vs. non lin } & \multicolumn{2}{|c|}{ sym vs. asym } & \multicolumn{2}{|c|}{$h_{t}$ vs. $f\left(h_{t}\right)$} & \multicolumn{2}{|c|}{ cst par vs. st } & \multicolumn{2}{|c|}{ std vs. comp } \\
\hline & 0.736 & 0.620 & 0.735 & 0.609 & 0.717 & 0.498 & 0.616 & 0.756 & 0.694 & 0.511 \\
\hline DCC & 0.727 & 0.607 & 0.723 & 0.597 & 0.705 & 0.484 & 0.618 & 0.743 & 0.681 & 0.500 \\
\hline DDCC & 0.717 & 0.605 & 0.719 & 0.598 & 0.701 & 0.481 & 0.617 & 0.742 & 0.679 & 0.516 \\
\hline $\mathrm{ADCC}$ & 0.718 & 0.601 & 0.718 & 0.595 & 0.699 & 0.477 & 0.615 & 0.739 & 0.676 & 0.518 \\
\hline \multicolumn{11}{|c|}{ ITM (334 contracts) } \\
\hline $\mathrm{CCC}$ & 0.446 & 0.377 & 0.426 & 0.380 & 0.432 & 0.310 & 0.387 & 0.436 & 0.416 & 0.329 \\
\hline DCC & 0.435 & 0.367 & 0.415 & 0.370 & 0.422 & 0.299 & 0.377 & 0.427 & 0.405 & 0.319 \\
\hline DDCC & 0.434 & 0.367 & 0.415 & 0.372 & 0.422 & 0.297 & 0.378 & 0.428 & 0.406 & 0.330 \\
\hline $\mathrm{ADCC}$ & 0.431 & 0.362 & 0.411 & 0.368 & 0.418 & 0.293 & 0.374 & 0.423 & 0.400 & 0.329 \\
\hline \multicolumn{11}{|c|}{ DITM (497 contracts) } \\
\hline $\mathrm{CCC}$ & 0.367 & 0.338 & 0.354 & 0.342 & 0.364 & 0.303 & 0.340 & 0.374 & 0.361 & 0.295 \\
\hline DCC & 0.363 & 0.334 & 0.349 & 0.338 & 0.359 & 0.301 & 0.336 & 0.370 & 0.357 & 0.292 \\
\hline DDCC & 0.364 & 0.334 & 0.351 & 0.339 & 0.360 & 0.300 & 0.338 & 0.371 & 0.358 & 0.299 \\
\hline $\mathrm{ADCC}$ & 0.362 & 0.331 & 0.348 & 0.336 & 0.357 & 0.297 & 0.334 & 0.368 & 0.354 & 0.299 \\
\hline
\end{tabular}

Note: lin (non lin): models linear (non linear) in $\epsilon_{t}^{2}$, sym (asym): models with symmetric (asymmetric) impact of shocks wrt the sign of the shock, $h_{t}\left(f\left(h_{t}\right)\right)$ : models where the variance (a function of the variance) is explicitly modelled, cst (st): models with constant parameters (smooth transition), std (comp): standard GARCH (component GARCH). See Table 6 for the specific models belonging to each group. 
Table 9: Absolute deviation losses in dollars by maturity

\begin{tabular}{|c|c|c|c|c|c|c|c|c|c|c|}
\hline \multicolumn{11}{|c|}{$\begin{array}{l}\text { Panel A: Gaussian innovations } \\
\text { Characteristics of the marginal variances }\end{array}$} \\
\hline \multicolumn{10}{|c|}{ ST (428 contracts) } & comp \\
\hline $\mathrm{CCC}$ & 0.189 & 0.173 & 0.186 & 0.173 & 0.186 & 0.157 & 0.176 & 0.185 & 0.182 & 0.162 \\
\hline DCC & 0.186 & 0.168 & 0.182 & 0.168 & 0.180 & 0.156 & 0.171 & 0.181 & 0.177 & 0.159 \\
\hline DDCC & 0.194 & 0.179 & 0.192 & 0.178 & 0.192 & 0.162 & 0.181 & 0.191 & 0.188 & 0.167 \\
\hline $\mathrm{ADCC}$ & 0.183 & 0.167 & 0.180 & 0.166 & 0.180 & 0.151 & 0.169 & 0.179 & 0.175 & 0.156 \\
\hline \multicolumn{11}{|c|}{ MT (335 contracts) } \\
\hline $\mathrm{CCC}$ & 0.412 & 0.380 & 0.423 & 0.371 & 0.409 & 0.341 & 0.381 & 0.425 & 0.408 & 0.325 \\
\hline DCC & 0.403 & 0.370 & 0.413 & 0.363 & 0.399 & 0.330 & 0.372 & 0.416 & 0.398 & 0.326 \\
\hline $\mathrm{DDCC}$ & 0.412 & 0.377 & 0.420 & 0.370 & 0.407 & 0.337 & 0.379 & 0.422 & 0.406 & 0.322 \\
\hline $\mathrm{ADCC}$ & 0.399 & 0.365 & 0.410 & 0.357 & 0.395 & 0.326 & 0.367 & 0.411 & 0.394 & 0.311 \\
\hline \multicolumn{11}{|c|}{ LT (474 contracts) } \\
\hline $\mathrm{CCC}$ & 0.929 & 0.955 & 1.068 & 0.888 & 0.951 & 0.942 & 0.919 & 1.094 & 1.035 & 0.664 \\
\hline DCC & 0.924 & 0.945 & 1.061 & 0.881 & 0.937 & 0.944 & 0.911 & 1.085 & 1.025 & 0.690 \\
\hline DDCC & 0.898 & 0.927 & 1.035 & 0.862 & 0.963 & 0.916 & 0.891 & 1.064 & 1.005 & 0.637 \\
\hline ADCC & 0.918 & 0.941 & 1.055 & 0.874 & 0.938 & 0.926 & 0.906 & 1.079 & 1.021 & 0.650 \\
\hline
\end{tabular}

Panel B: Laplace innovations

Characteristics of the marginal variances

\begin{tabular}{|c|c|c|c|c|c|c|c|c|c|c|}
\hline \multicolumn{11}{|c|}{$\begin{array}{r}\text { sym vs. asym } h_{t} \text { vs. } f\left(h_{t}\right) \\
\text { ST }(428 \text { contracts })\end{array}$} \\
\hline CCC & 0.197 & 0.177 & 0.190 & 0.179 & 0.193 & 0.158 & 0.181 & 0.190 & 0.187 & 0.170 \\
\hline DCC & 0.193 & 0.174 & 0.187 & 0.175 & 0.189 & 0.155 & 0.177 & 0.188 & 0.183 & 0.166 \\
\hline DDCC & 0.193 & 0.173 & 0.185 & 0.175 & 0.189 & 0.154 & 0.177 & 0.186 & 0.182 & 0.169 \\
\hline $\mathrm{ADCC}$ & 0.191 & 0.171 & 0.185 & 0.174 & 0.187 & 0.152 & 0.176 & 0.185 & 0.180 & 0.168 \\
\hline \multicolumn{11}{|c|}{ MT (335 contracts) } \\
\hline $\mathrm{CCC}$ & 0.411 & 0.352 & 0.392 & 0.355 & 0.398 & 0.296 & 0.362 & 0.395 & 0.381 & 0.321 \\
\hline DCC & 0.400 & 0.342 & 0.381 & 0.346 & 0.388 & 0.286 & 0.352 & 0.387 & 0.371 & 0.312 \\
\hline DDCC & 0.400 & 0.342 & 0.382 & 0.348 & 0.389 & 0.284 & 0.353 & 0.388 & 0.372 & 0.320 \\
\hline $\mathrm{ADCC}$ & 0.398 & 0.338 & 0.378 & 0.342 & 0.385 & 0.281 & 0.348 & 0.384 & 0.368 & 0.309 \\
\hline \multicolumn{11}{|c|}{ LT (474 contracts) } \\
\hline $\mathrm{CCC}$ & 0.862 & 0.743 & 0.852 & 0.735 & 0.845 & 0.610 & 0.750 & 0.896 & 0.828 & 0.598 \\
\hline DCC & 0.854 & 0.730 & 0.839 & 0.724 & 0.833 & 0.599 & 0.739 & 0.882 & 0.816 & 0.588 \\
\hline DDCC & 0.844 & 0.729 & 0.839 & 0.726 & 0.830 & 0.597 & 0.739 & 0.883 & 0.815 & 0.610 \\
\hline $\mathrm{ADCC}$ & 0.844 & 0.723 & 0.835 & 0.721 & 0.827 & 0.591 & 0.735 & 0.878 & 0.809 & 0.612 \\
\hline
\end{tabular}

Note: lin (non lin): models linear (non linear) in $\epsilon_{t}^{2}$, sym (asym): models with symmetric (asymmetric) impact of shocks wrt the sign of the shock, $h_{t}\left(f\left(h_{t}\right)\right)$ : models where the variance (a function of the variance) is explicitly modelled, cst (st): models with constant parameters (smooth transition), std (comp): standard GARCH (component GARCH). See Table 6 for the specific models belonging to each group. 

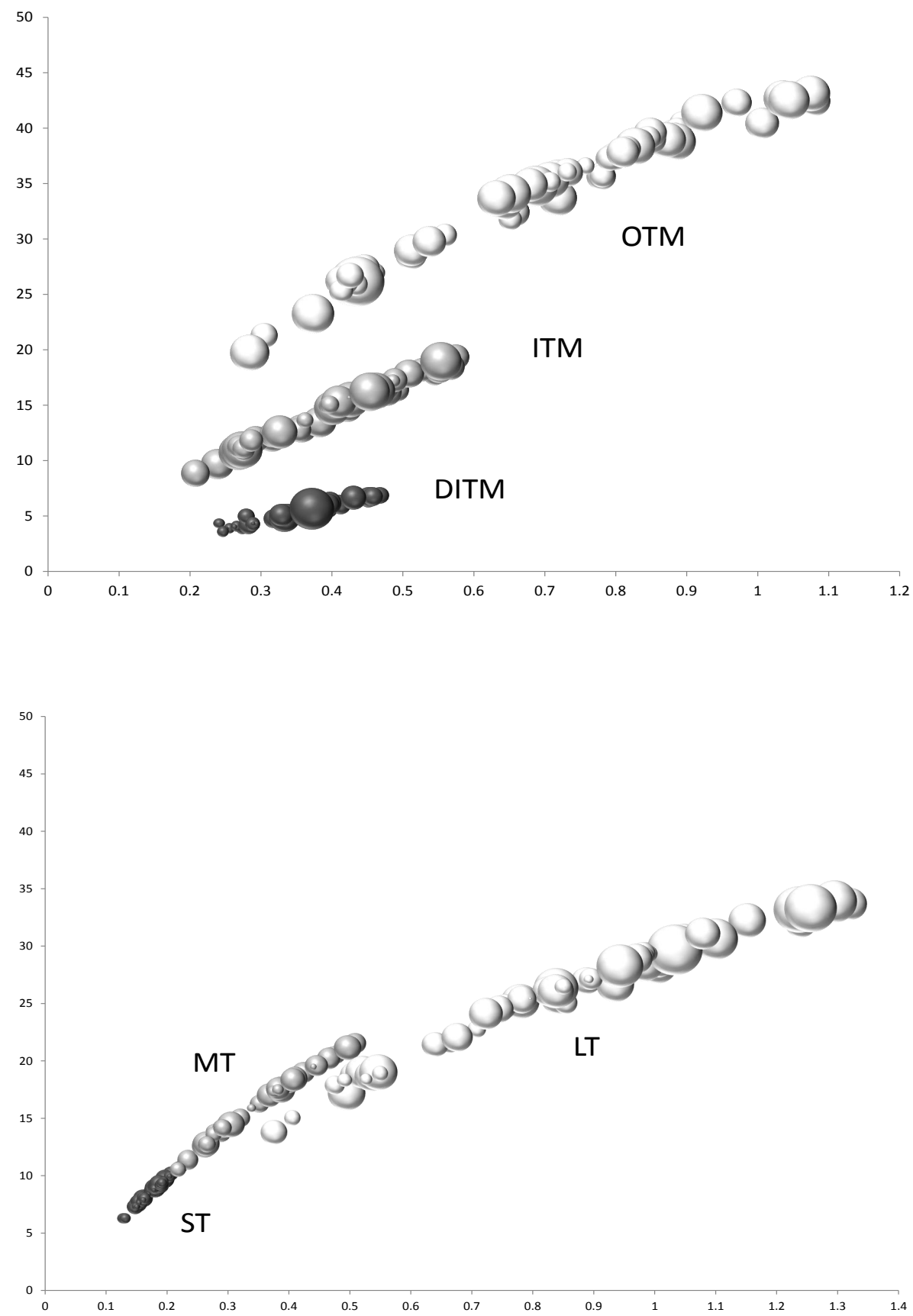

Figure 4: Models' ranking by Moneyness (top) and Maturity (bottom) Note: MAD (x-axis) and MARD (y-axis). Each bubble identifies a group of correlation models (CCC, DCC, DDCC, ADCC) characterized by the same specifications for the variance of the marginal processes. The bubbles are centered around the within group average loss, their diameter is the range computed on the MAD. 
the largest standardized relative performance. This process is repeated until non-rejection of the null occurs, thus allowing to construct a $(1-\alpha)$-confidence set for the best forecast in $\mathcal{M}^{0}$.

The MCS approach has been applied for all options and for each category of moneyness and maturity. The results are summarized in Table 10 for the MAD loss. The MARD results are in line with this and presented in Table 14 of Appendix 1. When considering all option contracts, the MCS consists of a single model allowing for asymmetry in the variances and correlations, non-linearity and conditional leptokurtosis, i.e., the asymmetric DCC model with 2-component TARCH marginal variances and Laplace conditional density. A more informative picture appears when we examine the contracts grouped by maturity/moneyness. As appears in Table 8, OTM and, to some extent ITM, contracts are the most difficult to price, showing the largest losses and loss differentials between models. The MCS is thus relatively small and reflects the large variability between model performances (within the range $0.27 \$-1.08 \$$ ). The MCS does not reject the hypothesis of constant correlation (when coupled with a sufficiently sophisticated model for the marginal variances) but strongly supports the Laplace density against the Gaussian.

Differently, DITM contracts are relatively easier to price and hence characterized by relatively close differences between models and an overall good accuracy (within the range 0.24-0.47). In line with this evidence, the MCS suggests the absence of statistically relevant gains from the choice of the distribution or the model for the correlation (the hypothesis of constant correlation is not rejected). However, there is still evidence of significant gains from non-linearity, asymmetry, and 2-component modelling strategies.

A different picture emerges when we focus on the maturity structure of the set of contracts under consideration. Short maturity contracts show extremely small differences in performances between models, e.g., the losses lie in the band $0.12 \$-0.21 \$$. However, the MCS delivers a singleton, which indicates that although models' sample performances are extremely close, they are also extremely stable thus allowing to efficiently discriminate between models. It is worth noting also that this is the only case where the Laplace assumption generates systematically larger losses than the pricing under Gaussianity. As the maturity increases, accurately pricing contracts becomes more difficult and we see large differences between model performances (within the range $0.37 \$-1.30 \$$ ). For very long maturities, the 
Table 10: Model confidence sets (MAD loss, $\alpha=1 \%$ )

\begin{tabular}{|c|c|c|c|c|c|}
\hline & & Correlation & Variances & Distribution & Loss \\
\hline \multicolumn{2}{|l|}{ All options } & $\mathrm{ADCC}$ & 2C(I)Tarch & Laplace & 0.243 \\
\hline \multirow{42}{*}{ Moneyness } & \multirow{8}{*}{ OTM } & $\mathrm{ADCC}$ & 2C(I)Tarch & Laplace & 0.276 \\
\hline & & DDCC & 2C(I)Tarch & Laplace & 0.278 \\
\hline & & DCC & 2C(I)Tarch & Laplace & 0.286 \\
\hline & & CCC & 2C(I)Tarch & Laplace & 0.298 \\
\hline & & $\mathrm{ADCC}$ & $\operatorname{Agarch}(b)$ & Laplace & 0.299 \\
\hline & & DDCC & $\operatorname{Agarch}(b)$ & Laplace & 0.301 \\
\hline & & DCC & $\operatorname{Agarch}(\mathrm{b})$ & Laplace & 0.303 \\
\hline & & $\mathrm{CCC}$ & $\operatorname{Agarch}(b)$ & Laplace & 0.315 \\
\hline & ITM & $\mathrm{ADCC}$ & 2C(I)Tarch & Laplace & 0.201 \\
\hline & \multirow{33}{*}{ DITM } & $\mathrm{ADCC}$ & $\operatorname{Agarch}(b)$ & Gaussian & 0.239 \\
\hline & & DCC & $\operatorname{Agarch}(b)$ & Gaussian & 0.239 \\
\hline & & $\mathrm{CCC}$ & $\operatorname{Agarch}(b)$ & Gaussian & 0.242 \\
\hline & & $\mathrm{ADCC}$ & 2C(I)Tarch & Laplace & 0.244 \\
\hline & & DDCC & $\operatorname{Agarch}(b)$ & Gaussian & 0.244 \\
\hline & & DDCC & 2C(I)Tarch & Laplace & 0.245 \\
\hline & & DCC & 2C(I)Tarch & Laplace & 0.247 \\
\hline & & $\mathrm{CCC}$ & 2C(I)Tarch & Laplace & 0.250 \\
\hline & & $\mathrm{ADCC}$ & $2 \mathrm{C}(\mathrm{I}) \mathrm{Garch}$ & Laplace & 0.251 \\
\hline & & DDCC & $2 \mathrm{C}(\mathrm{I}) \mathrm{Garch}$ & Laplace & 0.252 \\
\hline & & CCC & $2 \mathrm{C}(\mathrm{I})$ Garch & Laplace & 0.253 \\
\hline & & DCC & $2 \mathrm{C}(\mathrm{I}) \mathrm{Garch}$ & Laplace & 0.253 \\
\hline & & $\mathrm{ADCC}$ & $2 \mathrm{C}(\mathrm{I}) \mathrm{Garch}$ & Gaussian & 0.254 \\
\hline & & DDCC & $2 \mathrm{C}(\mathrm{I})$ Garch & Gaussian & 0.255 \\
\hline & & DCC & $2 \mathrm{C}(\mathrm{I})$ Garch & Gaussian & 0.256 \\
\hline & & $\mathrm{CCC}$ & 2C(I)Garch & Gaussian & 0.260 \\
\hline & & $\mathrm{ADCC}$ & 2C(I)Nagarch & Laplace & 0.261 \\
\hline & & DDCC & 2C(I)Nagarch & Laplace & 0.262 \\
\hline & & $\mathrm{ADCC}$ & 2C(I)Nagarch & Gaussian & 0.263 \\
\hline & & $\mathrm{CCC}$ & 2C(I)Nagarch & Laplace & 0.264 \\
\hline & & $\mathrm{DCC}$ & 2C(I)Nagarch & Gaussian & 0.264 \\
\hline & & DCC & 2C(I)Nagarch & Laplace & 0.264 \\
\hline & & DDCC & 2C(I)Nagarch & Gaussian & 0.266 \\
\hline & & $\mathrm{CCC}$ & 2C(I)Nagarch & Gaussian & 0.269 \\
\hline & & $\mathrm{ADCC}$ & 2C(I)Tarch & Gaussian & 0.270 \\
\hline & & DCC & 2C(I)Tarch & Gaussian & 0.273 \\
\hline & & DDCC & 2C(I)Tarch & Gaussian & 0.276 \\
\hline & & $\mathrm{ADCC}$ & $\operatorname{Agarch}(b)$ & Laplace & 0.277 \\
\hline & & $\mathrm{ADCC}$ & Egarch & Laplace & 0.277 \\
\hline & & DDCC & $\operatorname{Agarch}(b)$ & Laplace & 0.277 \\
\hline & & DCC & $\operatorname{Agarch}(b)$ & Laplace & 0.278 \\
\hline & & DCC & Egarch & Laplace & 0.280 \\
\hline & & $\mathrm{CCC}$ & $\operatorname{Agarch}(b)$ & Laplace & 0.286 \\
\hline \multirow{10}{*}{ Maturity } & $\mathrm{ST}$ & $\mathrm{ADCC}$ & 2C(I)Tarch & Gaussian & 0.124 \\
\hline & $\mathrm{MT}$ & $\mathrm{ADCC}$ & 2C(I)Tarch & Laplace & 0.212 \\
\hline & \multirow{8}{*}{ LT } & $\mathrm{ADCC}$ & 2C(I)Tarch & Laplace & 0.368 \\
\hline & & DDCC & 2C(I)Tarch & Laplace & 0.370 \\
\hline & & $\mathrm{DCC}$ & 2C(I)Tarch & Laplace & 0.378 \\
\hline & & CCC & $2 \mathrm{C}(\mathrm{I}) \operatorname{Tarch}$ & Laplace & 0.388 \\
\hline & & DDCC & $\operatorname{Agarch}(\mathrm{b})$ & Laplace & 0.401 \\
\hline & & $\mathrm{ADCC}$ & $\operatorname{Agarch}(b)$ & Laplace & 0.402 \\
\hline & & DCC & $\operatorname{Agarch}(b)$ & Laplace & 0.406 \\
\hline & & $\mathrm{CCC}$ & $\operatorname{Agarch}(b)$ & Laplace & 0.414 \\
\hline
\end{tabular}


MCS delivers a relatively small MCS. Gaussianity is rejected as well as symmetry and linearity in the marginal variances. Also in this case there is no significant gain in modelling the dynamics of the conditional correlation. The rejection of the dynamic correlation specification is in some case somewhat surprising. In fact, it is likely that the functional forms of the correlations models considered in this paper are not sufficient in the thirty dimensional case of the DJIA (e.g. two DCC parameters for 435 correlations), and therefore yield biased correlation forecasts. Evidence of this has also been reported by Audrino (2011) and Laurent, Rombouts, and Violante (2011).

\section{Conclusion}

Multivariate volatility models have been used extensively to model financial data and forecasts from these models are typically used as inputs in empirical asset pricing. This is particularly important for derivative pricing where the underlying of some of the most liquidly traded options, the index options, are portfolios of equally weighted assets. Despite the large availability of multivariate models of asset returns, the problem of model selection based on derivative pricing accuracy has received little attention. This paper investigates the value of model sophistication by considering a large number of high dimensional GARCH models and measuring performance in terms of Dow Jones Industrial Average option pricing accuracy. Since the option price does not only depend on the conditional variance matrix but also on other conditional moments, we are actually able to evaluate the full forecasting model.

In total we consider 248 multivariate GARCH models differing along three dimensions: the specification of the conditional variance, the conditional correlation, and the innovation distribution. The results of our application are first of all that in general more complicated models provide better option pricing forecasts. It turns out that the most important improvements in pricing come from increasing the sophistication in the marginal variance processes and from relaxing the Gaussian innovation for a Laplace innovation assumption. Enriching the model with more complex correlation models, and relaxing a Gaussian innovation for a Laplace innovation assumption improves the pricing in a smaller way. Overall, increasing model sophistication can reduce the dollar loss up to $60 \%$. The model that performs best, according to the model confidence test, is the two component threshold GARCH in combination with an asymmetric DCC structure and Laplace innovations. 
The results of this paper provide clear support for the use of models beyond standard multivariate volatility models for option pricing. However, the best models are often close to the boundary of sophistication. Since we consider only four correlation type specifications and two relatively close innovation densities, compared to the thirty-four univariate volatility models, it is expected that more flexible correlation models, e.g. Audrino and Trojani (2011), and especially innovation densities (which will require further developments for feasible option pricing) will further enhance the option pricing performance. An example is the dynamic copula approach of Fengler, Herwartz, and Werner (2010). Finally, given the evidence for example in Driessen, Maenhout, and Vilkov (2009), another challenging extension is to price correlation risk. This would require additional parameters and one step estimation in a thirty dimensional setup. 


\section{Appendix 1: results for mean absolute deviation loss function}

Table 11: Mean absolute relative deviation losses in percentages within each class of models

\begin{tabular}{|c|c|c|c|c|c|c|c|c|c|c|}
\hline \multirow{4}{*}{$\begin{array}{l}\text { CCC } \\
\text { DCC } \\
\text { DDCC } \\
\text { ADCC }\end{array}$} & \multicolumn{9}{|c|}{$\begin{array}{c}\text { Panel A: Gaussian innovations } \\
\text { Characteristics of the marginal variances }\end{array}$} & \multirow[b]{2}{*}{ comp } \\
\hline & lin vs. & non lin & sym vs. & asym & $h_{t}$ vs. & $f\left(h_{t}\right)$ & cst pa & vs. st & std vs. & \\
\hline & $\begin{array}{l}18.86 \\
18.48 \\
18.71\end{array}$ & $\begin{array}{l}18.17 \\
17.75 \\
18.01\end{array}$ & $\begin{array}{l}19.72 \\
19.45 \\
19.55\end{array}$ & $\begin{array}{l}17.67 \\
17.55 \\
17.51\end{array}$ & $\begin{array}{l}18.84 \\
18.55 \\
18.69\end{array}$ & $\begin{array}{l}17.22 \\
16.39 \\
17.03\end{array}$ & $\begin{array}{l}18.05 \\
17.75 \\
17.89\end{array}$ & $\begin{array}{l}19.88 \\
19.56 \\
19.73\end{array}$ & $\begin{array}{l}19.25 \\
18.96 \\
19.11\end{array}$ & $\begin{array}{l}15.43 \\
15.28 \\
15.19\end{array}$ \\
\hline & 18.55 & 17.70 & 19.19 & 17.30 & 18.41 & 16.81 & 17.60 & 19.54 & 18.81 & 15.03 \\
\hline
\end{tabular}

Panel B: Laplace innovations

Characteristics of the marginal variances

\begin{tabular}{lcccccccccc} 
& \multicolumn{1}{c}{ lin vs. non lin } & \multicolumn{2}{c}{ sym vs. asym } & $h_{t}$ vs. $f\left(h_{t}\right)$ & cst par vs. st & std vs. comp \\
CCC & 18.47 & 16.43 & 18.17 & 16.38 & 18.10 & 14.34 & 16.68 & 18.45 & 17.62 & 14.84 \\
DCC & 18.24 & 16.15 & 17.90 & 16.11 & 17.86 & 14.04 & 16.41 & 18.22 & 17.36 & 14.57 \\
DDCC & 18.16 & 16.10 & 17.87 & 16.14 & 17.82 & 13.95 & 16.41 & 18.20 & 17.33 & 14.89 \\
ADCC & 18.12 & 16.00 & 17.81 & 16.05 & 17.75 & 13.84 & 16.33 & 18.11 & 17.22 & 14.88 \\
\hline
\end{tabular}

$\overline{\text { Note: lin (non lin): models linear (non linear) in } \epsilon_{t}^{2} \text {, sym (asym): models with symmetric }}$ (asymmetric) impact of shocks wrt the sign of the shock, $h_{t}\left(f\left(h_{t}\right)\right)$ : models where the variance (a function of the variance) is explicitly modelled, cst (st): models with constant parameters (smooth transition), std (comp): standard GARCH (component GARCH). See Table 6 for the specific models belonging to each group. 
Table 12: Absolute relative deviation losses in percentages by moneyness

\begin{tabular}{lccccccccccc}
\hline \hline & \multicolumn{8}{c}{ Panel A: Gaussian innovations } \\
& \multicolumn{10}{c}{ Characteristics of the marginal variances } \\
\cline { 2 - 11 } & lin vs. non lin & \multicolumn{1}{c}{ sym vs. asym } & $h_{t}$ vs. $f\left(h_{t}\right)$ & cst par vs. st & std vs. comp \\
CCC & 36.99 & 35.84 & 38.98 & 34.73 & 37.01 & 34.13 & 35.54 & 39.17 & 37.88 & 30.46 \\
DCC & 36.69 & 35.46 & 38.70 & 34.45 & 36.69 & 33.69 & 35.23 & 38.87 & 37.54 & 30.88 \\
DDCC & 36.67 & 35.46 & 38.61 & 34.37 & 36.68 & 33.70 & 35.17 & 38.84 & 37.56 & 29.95 \\
ADCC & 36.80 & 35.28 & 38.54 & 34.16 & 36.54 & 33.47 & 35.01 & 38.67 & 37.38 & 29.84 \\
& & & & ITM & $(334$ contracts) & & & & \\
CCC & 16.34 & 15.28 & 16.75 & 14.97 & 16.19 & 14.09 & 15.31 & 16.81 & 16.27 & 13.23 \\
DCC & 16.05 & 14.91 & 16.41 & 14.68 & 15.87 & 13.69 & 15.00 & 16.48 & 15.92 & 13.29 \\
DDCC & 16.22 & 15.13 & 16.61 & 14.83 & 16.07 & 13.91 & 15.18 & 16.66 & 16.16 & 13.02 \\
ADCC & 15.88 & 14.77 & 16.29 & 14.45 & 15.72 & 13.52 & 14.81 & 16.33 & 15.79 & 12.69 \\
& & & & DITM $(497$ contracts $)$ & & & & \\
CCC & 5.73 & 5.69 & 5.99 & 5.56 & 5.78 & 5.52 & 5.60 & 6.19 & 6.03 & 4.63 \\
DCC & 5.69 & 5.61 & 5.92 & 5.50 & 5.72 & 5.44 & 5.54 & 6.12 & 5.95 & 4.73 \\
DDCC & 5.71 & 5.68 & 5.96 & 5.55 & 6.23 & 5.51 & 5.59 & 6.18 & 6.02 & 4.60 \\
ADCC & 5.63 & 5.57 & 5.89 & 5.44 & 5.67 & 5.39 & 5.49 & 6.08 & 5.92 & 4.51 \\
\hline
\end{tabular}

Panel B: Laplace innovations

Characteristics of the marginal variances

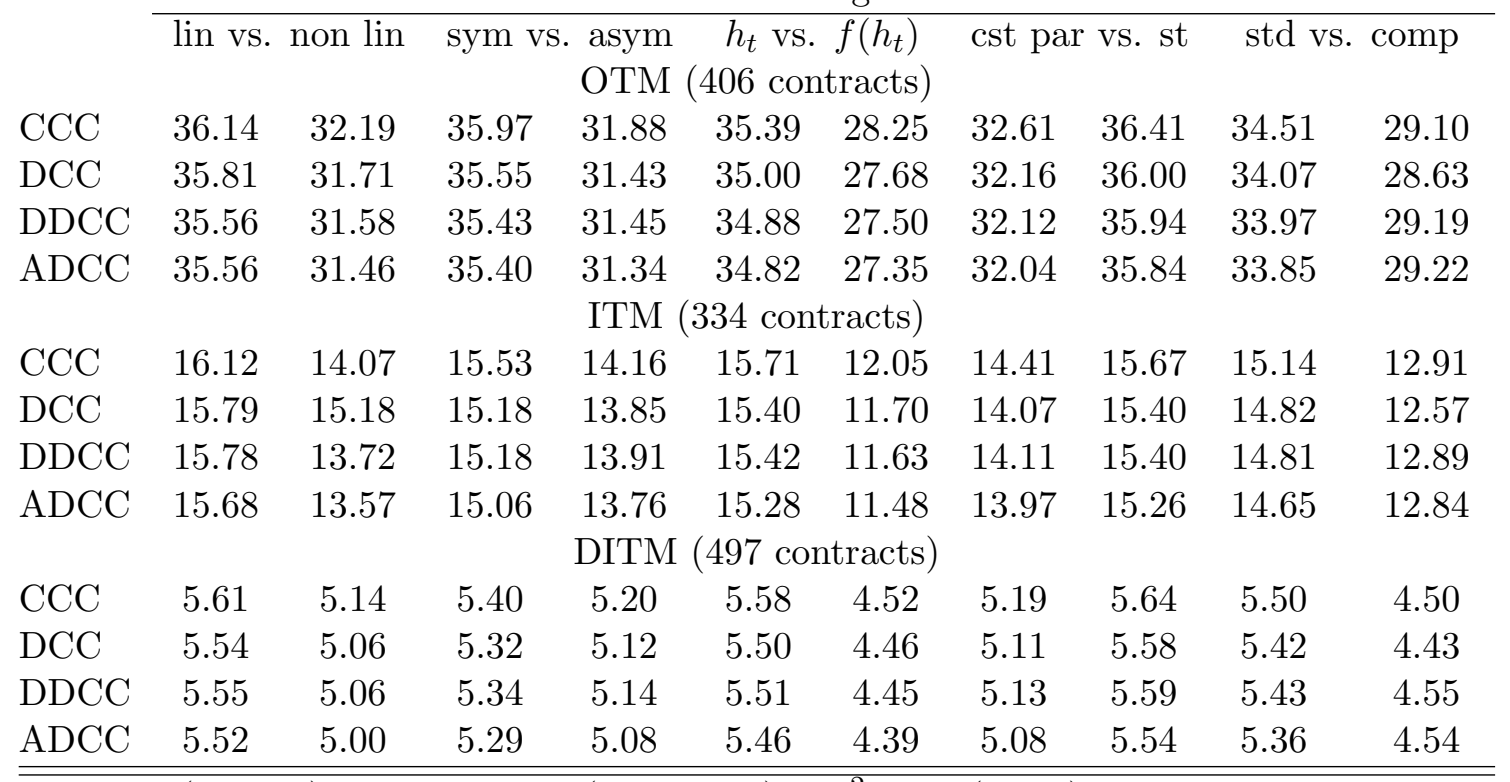

Note: lin (non lin): models linear (non linear) in $\epsilon_{t}^{2}$, sym (asym): models with symmetric (asymmetric) impact of shocks wrt the sign of the shock, $h_{t}\left(f\left(h_{t}\right)\right)$ : models where the variance (a function of the variance) is explicitly modelled, cst (st): models with constant parameters (smooth transition), std (comp): standard GARCH (component GARCH). See Table 6 for the specific models belonging to each group. 
Table 13: Absolute relative deviation losses in percentages by maturity

\begin{tabular}{|c|c|c|c|c|c|c|c|c|c|c|}
\hline \multicolumn{11}{|c|}{$\begin{array}{l}\text { Panel A: Gaussian innovations } \\
\text { Characteristics of the marginal variances }\end{array}$} \\
\hline \multirow[b]{2}{*}{$\mathrm{CCC}$} & \multirow{2}{*}{$\begin{array}{l}\text { lin vs. } \\
9.37\end{array}$} & \multirow{2}{*}{$\begin{array}{c}\text { non lin } \\
9.31\end{array}$} & \multicolumn{4}{|c|}{$\begin{array}{r}\text { sym vs. asym } h_{t} \text { vs. } f\left(h_{t}\right) \\
\text { ST }(428 \text { contracts })\end{array}$} & \multicolumn{2}{|c|}{ cst par vs. st } & \multicolumn{2}{|c|}{ std vs. comp } \\
\hline & & & 9.26 & 8.59 & 9.23 & 7.85 & 8.74 & 9.17 & 9.03 & 8.12 \\
\hline DCC & 9.18 & 8.39 & 9.04 & 8.42 & 9.02 & 7.62 & 8.55 & 98 & 8.81 & .08 \\
\hline DDCC & 9.48 & 8.73 & 9.37 & 8.71 & 9.35 & 7.95 & 8.86 & 9.30 & 9.16 & 8.18 \\
\hline $\mathrm{ADCC}$ & 9.09 & 8.30 & 8.99 & 8.27 & 8.94 & 7.52 & 8.44 & 8.88 & 8.73 & 7.81 \\
\hline \multicolumn{11}{|c|}{ MT (335 contracts) } \\
\hline $\mathrm{CCC}$ & 18.46 & 17.19 & 18.83 & 16.88 & 18.29 & 15.75 & 17.28 & 18.78 & 18.20 & 15.32 \\
\hline DCC & 18.17 & 16.83 & 18.52 & 16.61 & 17.99 & 15.35 & 16.98 & 18.48 & 17.87 & 15.37 \\
\hline DDCC & 18.42 & 17.04 & 18.72 & 16.76 & 18.22 & 15.54 & 17.16 & 18.66 & 18.10 & 15.14 \\
\hline $\mathrm{ADCC}$ & 18.04 & 16.69 & 18.41 & 16.37 & 17.85 & 15.17 & 16.79 & 18.32 & 17.73 & 14.79 \\
\hline \multicolumn{11}{|c|}{ LT (474 contracts) } \\
\hline $\mathrm{CCC}$ & 27.70 & 27.51 & 29.81 & 26.43 & 27.91 & 26.73 & 27.00 & 30.34 & 29.21 & 22.12 \\
\hline $\mathrm{DCC}$ & 27.57 & 27.28 & 29.65 & 26.28 & 27.73 & 26.48 & 26.83 & 30.15 & 29.02 & 22.62 \\
\hline DDCC & 27.24 & 27.07 & 29.34 & 26.00 & 27.47 & 26.28 & 26.55 & 29.90 & 28.80 & 21.57 \\
\hline ADCC & 27.44 & 27.18 & 29.54 & 26.10 & 27.64 & 26.34 & 26.69 & 30.03 & 28.93 & 21.73 \\
\hline
\end{tabular}

Panel B: Laplace innovations

Characteristics of the marginal variances lin vs. non lin sym vs. asym $h_{t}$ vs. $f\left(h_{t}\right) \quad$ cst par vs. st $\quad$ std vs. comp ST (428 contracts)

\begin{tabular}{lllllllllll} 
CCC & 9.59 & 8.65 & 9.27 & 8.72 & 9.40 & 7.73 & 8.83 & 9.24 & 9.09 & 8.29 \\
DCC & 9.37 & 8.47 & 9.10 & 8.51 & 9.21 & 7.55 & 8.63 & 9.10 & 8.90 & 8.10 \\
DDCC & 9.38 & 8.41 & 9.06 & 8.52 & 9.19 & 7.48 & 8.63 & 9.04 & 8.86 & 8.21 \\
ADCC & 9.31 & 8.35 & 9.02 & 8.44 & 9.13 & 7.42 & 8.56 & 8.99 & 8.79 & 8.17 \\
& & \multicolumn{7}{c}{ MT (335 contracts) } \\
CCC & 18.35 & 16.13 & 17.79 & 16.18 & 17.89 & 14.00 & 16.50 & 17.81 & 17.22 & 15.09 \\
DCC & 18.03 & 15.78 & 17.45 & 15.84 & 17.57 & 13.59 & 16.14 & 17.54 & 16.88 & 14.73 \\
DDCC & 18.01 & 15.74 & 17.43 & 15.91 & 17.58 & 13.51 & 16.17 & 17.55 & 16.87 & 15.04 \\
ADCC & 17.93 & 15.61 & 17.34 & 15.78 & 17.47 & 13.38 & 16.06 & 17.43 & 16.73 & 15.00 \\
& & & \multicolumn{7}{c}{ LT (474 contracts) } \\
CCC & 26.58 & 23.66 & 26.46 & 23.43 & 26.10 & 20.55 & 23.88 & 27.21 & 25.61 & 20.58 \\
DCC & 26.41 & 23.36 & 26.18 & 23.17 & 25.87 & 20.21 & 23.62 & 26.93 & 25.35 & 20.31 \\
DDCC & 26.20 & 23.30 & 26.14 & 23.19 & 25.79 & 20.11 & 23.61 & 26.92 & 25.30 & 20.82 \\
ADCC & 26.22 & 23.18 & 26.08 & 23.10 & 25.74 & 19.97 & 23.53 & 26.83 & 25.18 & 20.85 \\
\hline \hline
\end{tabular}

Note: lin (non lin): models linear (non linear) in $\epsilon_{t}^{2}$, sym (asym): models with symmetric (asymmetric) impact of shocks wrt the sign of the shock, $h_{t}\left(f\left(h_{t}\right)\right)$ : models where the variance (a function of the variance) is explicitly modelled, cst (st): models with constant parameters (smooth transition), std (comp): standard GARCH (component GARCH). See Table 6 for the specific models belonging to each group. 
Table 14: Model confidence sets (MARD loss, $\alpha=1 \%$ )

\begin{tabular}{|c|c|c|c|c|c|}
\hline & & Correlation & Variances & Distribution & Loss \\
\hline \multicolumn{2}{|l|}{ All options } & $\mathrm{ADCC}$ & 2C(I)TARCH & Laplace & 10.0 \\
\hline \multirow{15}{*}{ Moneyness } & \multirow{9}{*}{ OTM } & ADCC & 2C(I)TARCH & Laplace & 19.3 \\
\hline & & DDCC & 2C(I)TARCH & Laplace & 19.4 \\
\hline & & EDCC & 2C(I)TARCH & Laplace & 19.8 \\
\hline & & $\mathrm{CCC}$ & 2C(I)TARCH & Laplace & 20.4 \\
\hline & & $\mathrm{ADCC}$ & AGARCH(b) & Laplace & 21.0 \\
\hline & & DDCC & AGARCH(b) & Laplace & 21.0 \\
\hline & & EDCC & AGARCH(b) & Laplace & 21.2 \\
\hline & & $\mathrm{CCC}$ & AGARCH(b) & Laplace & 21.8 \\
\hline & & DDCC & 2C(I)TARCH & Gaussian & 22.9 \\
\hline & ITM & $\mathrm{ADCC}$ & 2C(I)TARCH & Laplace & 8.6 \\
\hline & DITM & $\mathrm{ADCC}$ & 2C(I)TARCH & Laplace & 3.5 \\
\hline & \multirow{4}{*}{$\mathrm{ST}$} & ADCC & 2C(I)TARCH & Gaussian & 6.1 \\
\hline & & $\mathrm{ADCC}$ & 2C(I)TARCH & Laplace & 6.1 \\
\hline & & EDCC & 2C(I)TARCH & Gaussian & 6.2 \\
\hline & & DDCC & 2C(I)TARCH & Laplace & 6.2 \\
\hline \multirow{9}{*}{ Maturity } & $\overline{\mathrm{MT}}$ & ADCC & 2C(I)TARCH & Laplace & 10.3 \\
\hline & \multirow{8}{*}{$\mathrm{LT}$} & $\mathrm{ADCC}$ & 2C(I)TARCH & Laplace & 13.4 \\
\hline & & DDCC & 2C(I)TARCH & Laplace & 13.5 \\
\hline & & EDCC & 2C(I)TARCH & Laplace & 13.8 \\
\hline & & $\mathrm{CCC}$ & 2C(I)TARCH & Laplace & 14.2 \\
\hline & & DDCC & AGARCH(b) & Laplace & 14.9 \\
\hline & & $\mathrm{ADCC}$ & AGARCH(b) & Laplace & 14.9 \\
\hline & & EDCC & $\operatorname{AGARCH}(\mathrm{b})$ & Laplace & 15.1 \\
\hline & & $\mathrm{CCC}$ & AGARCH(b) & Laplace & 15.3 \\
\hline
\end{tabular}




\section{References}

Audrino, F. (2011): "Forecasting Correlations during the late-2000s Financial Crisis: Shortrun Component, Long-run Component, and Structural Breaks," Department of Economics, University of St Gallen.

Audrino, F., And F. Trojani (2011): "A General Multivariate Threshold GARCH Model with Dynamic Conditional Correlations," Journal of Business and Economic Statistics, 29, $138-149$.

Bakshi, G., C. CaO, and Z. Chen (1997): "Empirical Performance of Alternative Option Pricing Models," Journal of Finance, 52, 2003-2049.

Bates, D. (1991): "The Crash of '87: Was it expected? The Evidence from Option Markets," Journal of Finance, 46, 1009-1044.

Bates, D. (2000): "Post-'87 Crash Fears in the S\&P 500 Futures Option Market," Journal of Econometrics, 94, 181-238.

Bollerslev, T. (2010): "Glossary to ARCH (GARCH)," in Volatility and Time Series Econometrics - Essays in Honor of Robert Engle, ed. by T. Bollerslev, J. Russell, and M. Watson. Oxford University Press.

Boyle, P. P. (1977): "Options: A Monte Carlo Approach," Journal of Financial Economics, $4,323-338$.

CAporin, M., and M. McAleer (2010): "Ranking Multivariate GARCH Models by Problem Dimension," SSRN eLibrary.

Chiriac, R., and V. Voev (2011): "Modelling and Forecasting Multivariate Realized Volatility," Journal of Applied Econometrics, 26(6), 922-947.

Christoffersen, P., C. Dorion, K. Jacobs, and Y. Wang (2010): "Volatility Components, Affine Restrictions, and Non-Normal Innovations," Journal of Business and Economic Statistics, 28(4), 483-502. 
Christoffersen, P., R. Elkamhi, B. Feunou, and K. Jacobs (2010): "Option Valuation with Conditional Heteroskedasticity and Non-Normality," Review of Financial Studies, $23,2139-2183$.

Christoffersen, P., S. Heston, and K. Jacobs (2006): "Option Valuation with Conditional Skewness," Journal of Econometrics, 131, 253-284.

Christoffersen, P., and K. Jacobs (2004): "Which GARCH Model for Option Valuation?," Management Science, 50(9), 1204-1221.

Christoffersen, P., K. Jacobs, C. Ornthanalai, and Y. Wang (2008): "Option Valuation with Long-run and Short-run Volatility Components," Journal of Financial Economics, 90, 272-297.

Da Fonseca, J., M. Grasselli, and C. Tebaldi (2007): "Option Pricing when Correlations are Stochastic: An Analytical Framework," Review of Derivatives Research, 10, $151-180$.

Driessen, J., P. J. Maenhout, and G. Vilkov (2009): "The Price of Correlation Risk: Evidence from Equity Options," Journal of Finance, LXIV(3), 1377-1406.

Eltoft, T. (2006): "On the Multivariate Laplace Distribution," IEEE Signal Processing Letters, 13, 300-303.

Engle, R. (2002): "Dynamic Conditional Correlation - a Simple Class of Multivariate GARCH Models," Journal of Business and Economic Statistics, 20, 339-350.

Engle, R., and R. Colacito (2006): "Testing and Valuing Dynamic Correlations for Asset Allocation," Journal of Business and Economic Statistics, 24, 238-253.

Engle, R., And J. MezRich (1995): "Grappling with GARCH," Risk, pp. 112-117.

Eraker, B. (2004): "Do Stock Prices and Volatility Jump? Reconciling Evidence from Spot and Option Prices," Journal of Finance, 59, 1367-1403.

Fengler, M. R., H. Herwartz, and C. Werner (2010): "A Dynamic Copula Approach to Recovering the Index Implied Volatility Skew," Forthcoming in Journal of Financial Econometrics. 
Fleming, J., C. Kirby, and B. Ostdiek (2001): "The Economic Value of Volatility Timing," Journal of Finance, LVI(1), 329-352.

- (2003): "The Economic Value of Volatility Timing using Realized Volatility," Journal of Financial Economics, 67(1), 473-509.

Giacomini, G., And H. White (2006): "Tests of Conditional Predictive Ability," Econometrica, 74, 1545-1578.

Gourieroux, C., and R. Sufana (2010): "Derivative Pricing with Wishart Multivariate Stochastic Volatility," Journal of Business and Economic Statistics, 28(3), 438-451.

Hansen, P., And A. Lunde (2005): "A Forecast Comparison of Volatility Models: Does Anything Beat a GARCH(1,1)?," Journal of Applied Econometrics, 20, 873-889.

(2006): "Consistent Ranking of Volatility Models," Journal of Econometrics, 131, $97-121$.

Hansen, P., A. Lunde, and J. Nason (2011): "The Model Confidence Set," Econometrica, $79,453-497$.

Heston, S. L., And S. NAndi (2000): "A Closed-Form GARCH Option Valuation Model," Review of Financial Studies, 13(3), 585-625.

Hsieh, K. C., and P. Ritchken (2005): "An Empirical Comparison of GARCH Option Pricing Models," Review of Derivatives Research, 8, 129-150.

Laurent, S., J. Rombouts, and F. Violante (2009): "On Loss Functions and Ranking Forecasting Performances of Multivariate Volatility Models," CIRANO discussion paper 2009-45.

(2011): "On the Forecasting Accuracy of Multivariate GARCH Models," Forthcoming in Journal of Applied Econometrics.

Longstaff, F. A., And E. S. Schwartz (2001): "Valuing American Options by Simulation: A Simple Least-Squares Approach," Review of Financial Studies, 14, 113-147.

PAN, J. (2002): "The Jump-risk Premia Implicit in Options: Evidence from an Integrated Time-series Study," Journal of Financial Economics, 63, 3-50. 
Patton, A. (2009): "Volatility Forecast Comparison Using Imperfect Volatility Proxies," Forthcoming in Journal of Econometrics.

Rombouts, J., and L. Stentoft (2011): "Multivariate Option Pricing with Time Varying Volatility and Correlations," Journal of Banking and Finance, 35, 2267-2281.

Stentoft, L. (2004): "Convergence of the Least Squares Monte Carlo Approach to American Option Valuation," Management Science, 50(9), 1193-1203.

(2005): "Pricing American Options when the Underlying Asset follows GARCH Processes," Journal of Empirical Finance, 12(4), 576-611.

— (2008): "American Option Pricing using GARCH Models and the Normal Inverse Gaussian Distribution," Journal of Financial Econometrics, 6(4), 540-582.

van Den Goorbergh, R., C. Genest, and B. Werker (2005): "Bivariate Option Pricing Using Dynamic Copula Models," Insurance: Mathematics and Economics, 37, 101-114.

Voev, V. (2009): "On the Economic Evaluation of Volatility Forecasts," CREATES Research Paper 2009-56.

Xekalaki, E., and S. Degiannakis (2010): ARCH Processes for Financial Applications. John Wiley and Sons.

Zhang, J., And D. GuÉgan (2008): "Pricing Bivariate Option under GARCH Processes with Time-varying Copula," Insurance: Mathematics and Economics, 42, 1095-1103. 